\title{
Accuracy of BLX and BLT guided implants in the edentulous maxilla: an in vivo study
}

\author{
Benjamin Andrew Kordusky \\ bakordusky@mix.wvu.edu
}

Follow this and additional works at: https://researchrepository.wvu.edu/etd

Part of the Oral and Maxillofacial Surgery Commons, Periodontics and Periodontology Commons, Prosthodontics and Prosthodontology Commons, and the Surgery Commons

\section{Recommended Citation}

Kordusky, Benjamin Andrew, "Accuracy of BLX and BLT guided implants in the edentulous maxilla: an in vivo study" (2020). Graduate Theses, Dissertations, and Problem Reports. 7544.

https://researchrepository.wvu.edu/etd/7544

This Thesis is protected by copyright and/or related rights. It has been brought to you by the The Research Repository @ WVU with permission from the rights-holder(s). You are free to use this Thesis in any way that is permitted by the copyright and related rights legislation that applies to your use. For other uses you must obtain permission from the rights-holder(s) directly, unless additional rights are indicated by a Creative Commons license in the record and/ or on the work itself. This Thesis has been accepted for inclusion in WVU Graduate Theses, Dissertations, and Problem Reports collection by an authorized administrator of The Research Repository @ WVU. For more information, please contact researchrepository@mail.wvu.edu. 
Accuracy of BLX and BLT guided implants in the edentulous maxilla: an in vivo study

Benjamin Andrew Kordusky, D.D.S.

\author{
Thesis submitted \\ to the School of Dentistry \\ at West Virginia University \\ in partial fulfillment of the requirements for the degree of \\ Master of Science in \\ Prosthodontics
}

\author{
Matthew S. Bryington, D.M.D., M.S., F.A.C.P. (Chair) \\ Gian Pietro Schincaglia, D.D.S., Ph.D. \\ Arif Salman Abdul Shakore, M.D.S \\ Department of Restorative Dentistry
}

\title{
Morgantown, West Virginia
}

2020

Keywords: Dental implants, guided surgery, guide accuracy, surgery accuracy, edentulous maxilla

Copyright 2020 Benjamin A. Kordusky 


\begin{abstract}
Accuracy of BLX and BLT guided implants in the edentulous maxilla: an in vivo study Benjamin Andrew Kordusky, D.D.S.
\end{abstract}

Objectives: To determine the accuracy of dental implants placed using a dual scan CBCT protocol with a SLA 3D printed mucosa supported surgical guide using a flapless surgical approach with regard to sleeve position, type of implant, and regional location in the maxillary arch.

Methods: Nine patients received 4 dental implants utilizing a fully guided, flapless approach with a mucosa supported SLA surgical guide with 3 fixation pins. Implants were immediately loaded using an attachment placed in an existing Maxillary complete denture. Accuracy of implant positions were evaluated by the Treatment Evaluation module of coDiagnostiX (DentalWings, Montreal, Canada). Statistical analysis was completed based on the sleeve position, type of implant, and regional location in the maxillary arch.

Results: An average angular deviation of $3.0^{\circ}$ was seen. An average 3D offset of 1.05 $\mathrm{mm}$ and $1.10 \mathrm{~mm}$ were seen at the base and tip of the implants respectively. A statistically significant difference was seen between BLT and BLX implants with respect to 3D offset of the implant platform. A statistically significant increase in average apical 3D offset of implants were seen in implants placed in posterior regions when compared to anterior regions.

Conclusions: A fully guided, flapless approach using Straumann BLT or BLX implants demonstrated an angular accuracy within $3^{\circ}$ and approximately $1 \mathrm{~mm}$ of $3 \mathrm{D}$ offset from pre-surgical planning. BLT implants were seen to have an increased degree of inaccuracy. Implants placed in posterior regions of the maxilla demonstrated a greater degree of inaccuracy than those placed in anterior regions. 


\section{ACKNOWLEGEMENTS}

Thank you to the following for contributions and guidance:

Dr. Matthew Bryington - Thank you for guidance and training on usage of coDiagnostiX and your training in my prosthodontic education.

Lyndsey Gray - Thank you for your expertise and willingness to take dual scan CBCTs for this project and for your support during this process.

Dr. Gian Pietro Schincaglia - Thank you for your expertise as a clinician and researcher in making this project a possibility.

Dr. Michele Agusto - Thank you for your dedication to this project and all of the time and effort put in to make this project possible.

Joanna Kordusky - Thank you for unwavering support throughout this challenging process.

I would like to thank Straumann for their donation of funds and materials to allow

this project to exist.

Finally I would like to thank the IRB at West Virginia University Office of Research Integrity and Compliance their consideration and approval of this project.

(IRB number 1801929813). 


\section{TABLE OF CONTENTS}

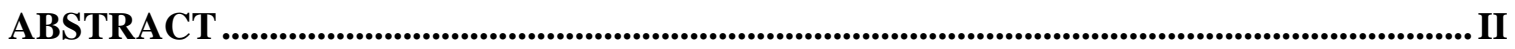

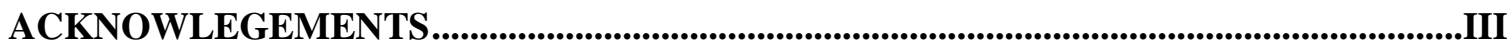

TABLE OF CONTENTS.........................................................................................

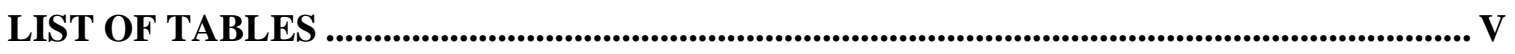

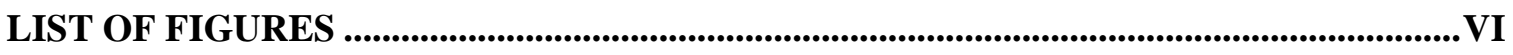

LIST OF ABBREVIATIONS........................................................................................

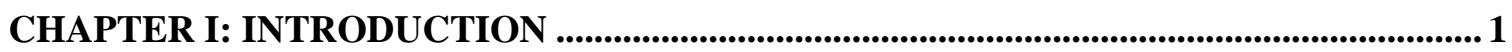

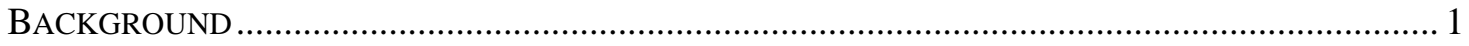

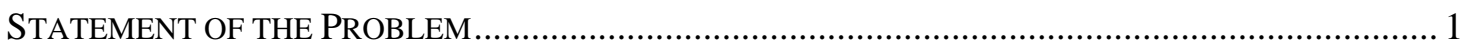

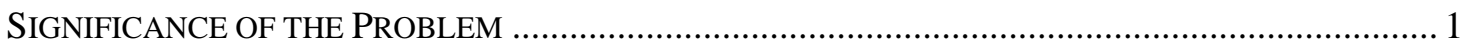

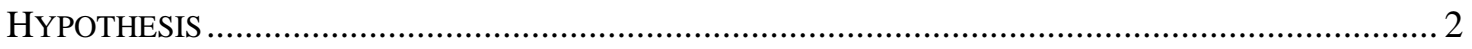

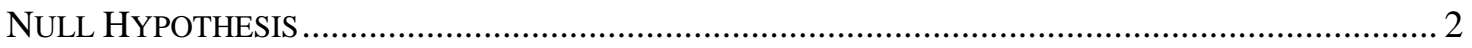

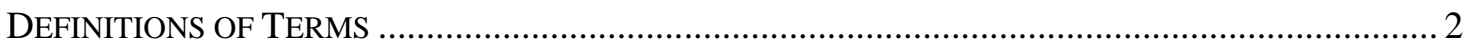

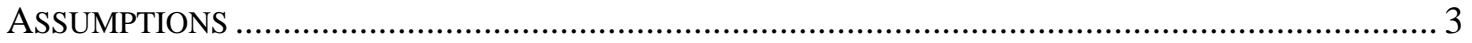

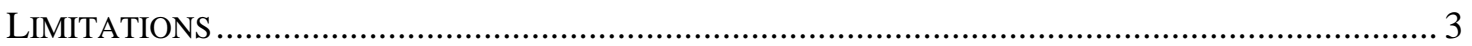

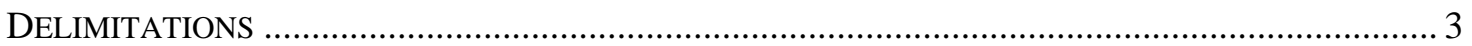

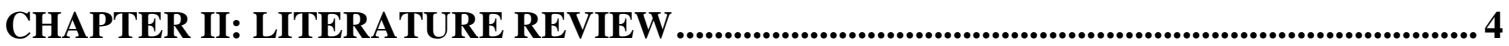

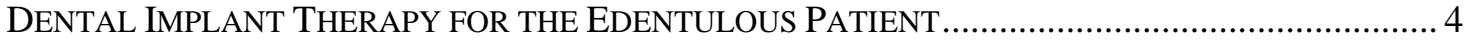

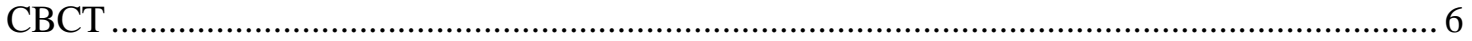

3D PRINTING

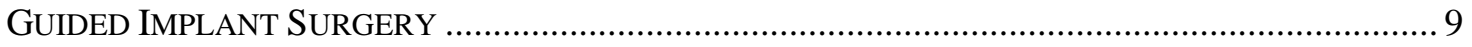

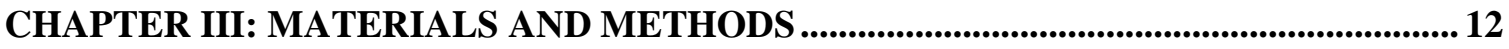

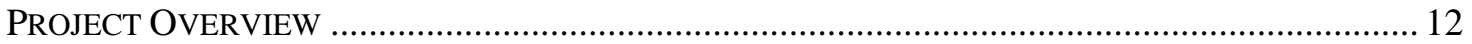

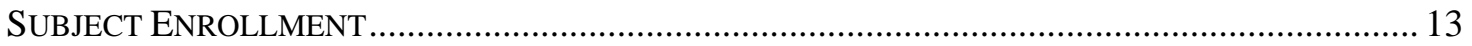

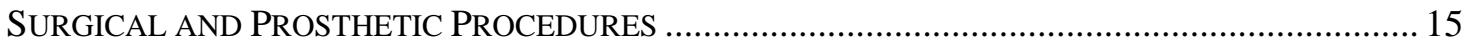

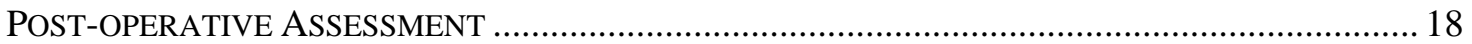

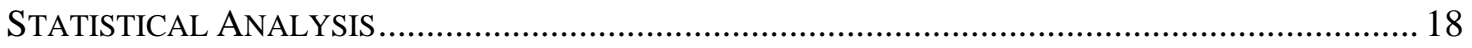

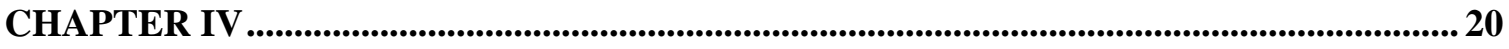

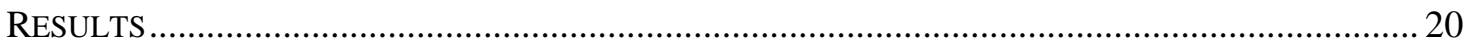

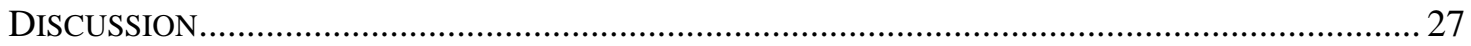

CHAPTER V: SUMMARY AND CONCLUSION ...................................................................... 31

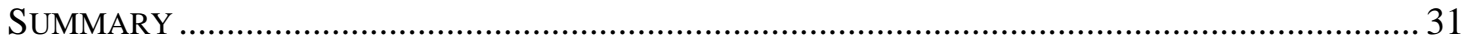

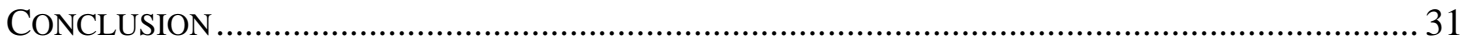

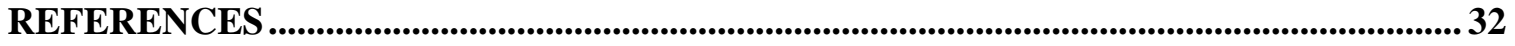




\section{LIST OF TABLES}

Table 1. Inclusion and exclusion criteria used during subject enrollment

Table 2. Patient Demographics and implant distribution based on length and design.

Table 3. Angular deviation and 3D offset of actual implant position compared to planned position.

Table 4. Mean angular deviation and 3D offset of actual implant position compared to planned position for different sleeve height settings.

Table 5. Mean angular deviation and 3D offset of actual implant position compared to planned position for different implant systems.

Table 6. Mean angular deviation and 3D offset of actual implant position compared to planned position for different implant locations. 


\section{LIST OF FIGURES}

Figure 1. Flowchart of project workflow

Figure 2. Occlusal view of example surgical guide design incorporating guide sleeves and fixation pin sleeves into duplicate of existing complete denture.

Figure 3 A and B. A. Immediate post-operative occlusal view of example patient following implant and abutment placement. B. Immediate post-operative view of intaglio of Maxillary prosthesis following housing pick up for the same example patient.

Figure 4. Example display of error values and display of pre-operative "planned" implant position displayed in blue and post-operative "actual" implant position displayed in red.

Figure 5. Comparison of mean angular deviation of actual implant position compared to planned implant position between different sleeve heights.

Figure 6. Comparison of mean 3D offset at base of actual implant position compared to planned implant position between different sleeve height settings.

Figure 7. Comparison of mean 3D offset at tip of actual implant position compared to planned implant position between different sleeve height settings.

Figure 8. Comparison of mean angular deviation of actual implant position compared to planned implant position between implant designs.

Figure 9. Comparison of mean 3D offset at base of actual implant position compared to planned implant position between different implant designs.

Figure 10. Comparison of mean 3D offset at tip of actual implant position compared to planned implant position between different implant designs. 
Figure 11. Comparison of mean angular deviation of actual implant position compared to planned implant position between different implant locations.

Figure 12. Comparison of mean 3D offset at base of actual implant position compared to planned implant position between different implant locations.

Figure 13. Comparison of mean 3D offset at tip of actual implant position compared to planned implant position between different implant locations. 


\section{LIST OF ABBREVIATIONS}

BLT- bone level tapered implant

BLX- bone level extreme

NC- narrow crossfit connection

RB- regular base connection

Mx- maxilla

SLA- stereolithographic 3D printing

VP- vat polymerization

CBCT- cone beam computed tomography

ISQ- implant stability quotient

3D- three dimensional

2D- two dimensional

FDK- Feldkamp-Davis-Kress algorithm

MPR- multiplanar reformatting 


\section{CHAPTER I: INTRODUCTION}

\section{Background}

Advances in implant surface technology, radiology, 3D printing technologies, and the application of these technologies to guided implant surgery have made dental implant therapies more widely available to those to whom it would benefit with a shortened treatment duration and more reasonable cost than previously possible1-13. Incorporation of the structure of the patients' prosthesis to the treatment planning software allows for a prosthetically driven implant treatment planning in the pre-surgical phase7,9,14. Current technology allows for a development of a pre-surgical plan and translation of the plan to the surgical phase of care by means of digital design and 3D printing to create a custom surgical guide6,7,9,13-20.

\section{Statement of the Problem}

How accurate are dental implants placed using a dual scan CBCT protocol with a SLA 3D printed mucosa supported surgical guide with 3 fixation pins using a flapless surgical approach? Does sleeve height setting from planned implant platform affect accuracy? Does implant design affect accuracy? Does regional location in maxillary arch affect accuracy?

\section{Significance of the Problem}

Accurate placement of dental implants is critical especially when a fixed solution is used or when approaching vital anatomic structures. There are a multitude of factors that can affect the level to which post-operative implant positions can deviate from presurgical planning 13,21-23. Mucosa supported guides in the edentulous patient can be particularly challenging due to the lack of rigidity of the soft tissue support13,16,22-24. The ability to accurately and predictably transfer the position of a pre-operative plan is critical to excellent implant dentistry. 


\section{Hypothesis}

There will be an increased level of inaccuracy when sleeve height from planned implant platform is increased. There will be an increased level of inaccuracy with $3.3 \mathrm{~mm}$ BLT implants when compared to $3.75 \mathrm{~mm}$ BLX implants are used. There will be an increased inaccuracy for implants placed in posterior maxillary regions when compared to anterior maxillary regions.

\section{Null Hypothesis}

There will be no difference in accuracy between sleeve heights from planned implant platform, implant design, or location in maxillary arch.

\section{Definitions of Terms}

Multiplanar reformatting- technology used by implant treatment planning software for visualization of axial, coronal, and sagittal views throughout the volume of the $3 \mathrm{D}$ reconstruction 10 .

Partially guided procedure- a surgical approach in which the osteotomy is completed using the surgical guide but the implant is placed without the surgical guide15,23.

Fully guided procedure- a surgical approach in which both the osteotomy and implant placement are completed with the surgical guide in place 15,23 .

Computer guided navigation- a dynamic process involving fixation of a template to the patient prior to CBCT evaluation to relate the position of the patient to the treatment planning and navigation software25-28.

Stereolithography- a vat polymerization (VP) method of 3D printing in which laser light is transmitted to an area of photopolymerizing liquid resin in a tank in a repeated manner 
as the build platform is moved further and further up in defined increments until the entire 3D object has been made19,29

SLA 3D printed surgical guides- a printed resin structure to house a guiding sleeve through which the osteotomy bur is guided to the planned surgical site to control angle and depth13,16,17,20,21,30-33.

\section{Assumptions}

1. It is assumed that the all surgical guides were consistently designed and $3 \mathrm{D}$ printed with similar accuracy.

2. It is assumed that all fiduciary markers were accurately identified and appropriately positioned digitally in coDiagnostiX software.

3. It is assumed that anatomic landmarks used to merge post-operative CBCTs with pre-operative plan were accurately identified and appropriately positioned digitally in coDiagnostiX software.

4. It is assumed that surgical protocol was consistent between all patients.

\section{Limitations}

1. Interim report of data collected as part of an ongoing prospective study

2. A patient population of 9 with a total of 34 implant sites available for statistical analysis.

3. 7 implant sites in BLT group and 27 implant sites in BLX group.

\section{Delimitations}

1. Limited to mucosa supported guides with 3 fixation pins.

2. Limited to surgical guides printed on Form 2 desktop printed with DentalSG resin.

3. Limited to outcomes of one experienced surgeon in one clinical setting. 


\section{Chapter II: Literature Review}

\section{Dental Implant Therapy for the Edentulous Patient}

The theory of osseointegration and its application to dental implant therapy was described by P.I. Brånemark based on his experimentation with a rabbit model 34 . He found that when titanium was placed in vital bone, that there was an apparent connection of the bone to the titanium that resisted dislodgement $2,34,35$. This connection resulted in a direct bone anchorage of a titanium dental implant to the bone to which a prosthesis could be attached to replace a patient's missing teeth35-37. Initial surgical and prosthetic protocols involved a sterile procedure with a submerged healing for 6 months or more followed by prosthetic loading after the period of submerged healing2,34,36,38.

Advancements in technology, surfaces, and techniques have allowed for alterations to the original surgical and prosthetic protocols1-3,5,11,12,34,36,38-41. Initial implant designs included a turned metal titanium screw without additional treatments, while modern implants consist of predominately titanium alloys with surface treatments to create a more osteoconductive moderately roughened surface1-3,34,39. The newer, moderately roughened dental implant surfaces have allowed for a significant reduction in the time between surgical implant placement and attachment of prosthetic teeth to the point that prosthetic connection can be completed immediately following placement with

a high degree of success and survival comparable to conventional protocols3-5,11,12,39-41. Recent studies have shown that not only are immediately placed implants for a locator retained mandibular overdenture as likely to be successful as delayed loaded implants, there is actually less radiographic bone loss around the implants at the 12 month follow up12. Evidence is available regarding the success of immediately loading maxillary implants with fixed restoration successfully, but evidence related to immediate loading of maxillary implants with a removable prosthesis is almost non-existent41. Further investigation into immediately loaded implants for maxillary removable prostheses is needed. 
Many dentists are now routinely incorporating dental implant therapy into everyday practice to replace single or multiple teeth as well as reconstruction of entire dental arches. Many patients with conventional complete dentures are at a functional and lifestyle deficit due to the inability of these tissue supported prosthesis to adequately replace function in addition to the potential lack of stability, support, and retention42-48. With a growing number of elderly patients, it is expected that there will be an increasing number of completely edentulous patients in need to dental care $42,43,48$. The use of dental implants has been shown to not only improve stability and retention of removable dental prostheses, but also improve the patient experience associated with daily life with a removable prosthesis43-48.

At best, it has been shown that the masticatory performance of a denture wearer is a little over $50 \%$ of the performance of a dentate individual 49 . Those with unstable and unretentive removable prostheses may have even more difficulty with speaking and chewing leading to further psychological consequences43. Many factors influence the retention, stability, and support of the maxillary conventional denture, but as we age many of these factors are negatively influenced resulting in a lack of comfort, retention, and stability with even a well made prosthesis. This lack of stability is the main factor influencing the patient's quality of life 47 . While many patients can adapt to edentulism and cope with their prostheses, there is a significant portion of the population are considered maladaptive and can benefit from more advanced tooth replacement solutions43.

For almost 20 years, the two implant mandibular overdenture has been the recommended first choice standard of care therapy for the edentulous mandibles. This recommendation was based on clinical and patient related factors8. A recent systematic review discussed the lack of literature related to implant supported dentures in the maxilla, but his review showed that at least 4 implants should be used in the edentulous maxilla50. Dental implants have been shown to decrease the rate of bone resorption while improving patients' ability to live their life with a removable prosthesis $8,43,44,46$. Not only does the additional stability allow for a more effective masticatory ability resulting in the 
ability to consume a more nutritious, healthful diet, but also allows for an improvement in self-confidence while speaking and interacting in social settings8,43-46.

Many implant companies have designed implants with the intent of achieving a higher level of primary stability to allow for immediate loading protocols in which the prosthetic connection is made at the time of implant placement5,7,41,51. One of these implant designs is the Straumann BLX (Straumann, Andover MA)51. The BLX is a fully tapered implant with a progressive, variable double thread design that allows for selfcutting, self-tapping, and self-grafting of the implant during placement51. It is designed with a reduced neck diameter to allow crestal bone preservation even in situations of high initial stability that could otherwise cause compression of the crestal bone51. This differs from other tapered implants in the same family that have a parallel body with only the apical $5 \mathrm{~mm}$ tapered that generally have less aggressive thread designs51. While often able to still achieve a good level of primary stability, these other designs cannot as predictably achieve high primary stability like that seen with more aggressive designs like the BLX implant in challenging scenarios like placement in the posterior maxilla with poorer quality bones1.

While there is an additional cost to include dental implant therapy into the treatment plans of the edentulous patient, many authors agree that the functional and psychosocial benefits outweigh the associated costs in many situations8,43-45,48. Advances in radiology, 3D printing technologies, and the application of these technologies to guided implant surgery that will be discussed later in this report have made dental implant therapies more widely available to those to whom it would benefit with a shortened treatment duration and more reasonable cost than previously possible.

\section{CBCT}

After a thorough clinical exam, one of the most important aspects of the presurgical evaluation of a potential dental implant patient is an appropriate radiographic examination52,53. Historically, two dimensional images such as periapical radiographs and 
panoramic radiographs have been used predominately in the pre-surgical assessment of dental implant sites52,53. These 2D imaging strategies have shortcomings however, such as, overlapping of anatomic structures and varying degrees of magnification that could lead to an unintentional encroachment of vital structures52-54. The inability to see concavities or thickness of width of bone only visible from a cross sectional view of a 3D image has led many dental implant therapy providers to lean on the added benefit on a 3 dimensional imaging method such as cone beam computed tomography (CBCT) in the pre-surgical assessment of dental implant patients52-54.

CBCTs are imaging machines with a similar footprint to a dental panoramic radiograph unit that have been utilized in the dental field since the late 1990s10. CBCTs are a radiologic study in which energy is converted into X-rays through the Bremsstrahlung effect which exit via a tube to a defined space known as the field of view (FOV)10. Any of the patients anatomic structures within the FOV are recorded as X-ray photons reach the flat plane detector that converts the X-rays into an electrical signal as the machine spins around the head of the patient10. The process to take a CBCT ranges from about 10 seconds to almost 1 minute depending on the machine, machine settings, and FOV 10. Most current CBCT machines utilize the Feldkamp-David-Kress (FDK) algorithm because of its speed and simplicity 10. During the process, several hundred 2D images are collected allowing them to later be reconstructed into a 3D rendering of the object imaged 10,53,54. The quality of a CBCT image is generally less than a medical CT but so is the dose of radiation received by the patient, while still generally being considered as acceptable from a pre-surgical assessment of a proposed dental implant site 10,53,55.

Many implant treatment planning software programs use multiplanar reformatting (MPR) to allow visualization of axial, coronal, and sagittal views throughout the volume of the 3D reconstruction10. These software programs also allow for manipulation of images and segmentation of 3D renderings at different settings to eliminate scatter of less dense structures 10,54. These segmentations allow the incorporation of *.stl files of the patients' existing dentition, existing prosthesis, and/or final prosthetic plan to the 
radiographic evaluation7,9,18. This allows for prosthetically driven implant site treatment planning and in some cases can allow for pre-fabrication of prosthetic parts to be used immediately following implant placement7,9,18.

Incorporation of prosthetic information of the edentulous arch to the implant treatment planning software requires additional imaging and sometimes radiographic markers14. This process is known as the dual scan protocol, and includes a CBCT scan of the patient wearing the denture with radiographic fiduciary markers or a duplicate of the denture in a radiopaque material as well as a CBCT scan of the denture with radiographic fiduciary markers or a duplicate of the denture in a radiopaque material on its own 14. This allows for an overlapping and an appropriate positioning of the prosthesis in the treatment planning software. Once the prosthesis is properly positioned in the software, the provider can use the information provided by the planned or existing position of the teeth to derive a prosthetically driven treatment plan for the proposed implant sites6,7,9,14.

\section{D Printing}

An additive manufacturing process like $3 \mathrm{D}$ printing is inherently different from subtractive processes like milling in many ways 19. It is generally a more affordable process because it is less wasteful19. This is because instead of beginning with a large block or puck of material as is common in subtractive manufacturing processes, 3D printing is an additive process in which objects are built layer by layer without having to waste excess materials 19,29. The primary application of additive manufacture to dental implantology is in the use of Stereolithography (SLA) 3D printing technology29.

SLA is a vat polymerization (VP) method of 3D printing in which laser light is transmitted to an area of photopolymerizing liquid resin in a tank in a repeated manner as the build platform is moved further and further up in defined increments until the entire 3D object has been made19,29. This results in a series of 2D planes stacked on one another until the final planned 3D object is constructed 19 . This process can be used for large or small objects and results in a final product with excellent surface detail and accuracy 19. 
The mechanical properties of these products can be poor due to the fact that they are polymers and behave as such19. These poor mechanical properties lead to a more fragile material that can break if fabricated with insufficient bulk and can have flexure across the body of the material prior to overt failure due to fracture 19,23 .

The dental implant industry has utilized the technological advances in the additive manufacture process to simplify and improve surgical outcomes related to dental implant placement through the use of SLA 3D printed surgical guides6,9,13,14,16,19-23,29-31. These products are available for purchase at a reasonable price that can be afforded by many dental practices for routine use33. Desktop 3D printers have improved in their ability to create accurate implant surgical guides in a reasonable amount of time for a price that can be passed along to the patient to improve the overall outcome of the treatment and decrease the duration of the surgical visit9,33.

\section{Guided Implant Surgery}

For many years, dental implants were placed in the most surgically convenient position based on the contours of the patient's bone structure in an attempt to have an implant in bone to which prosthetic teeth could be attached2,36,38. These positions were not always ideal for optimal biomechanics or esthetics2,9,36. This was done because of limitations in material technologies for implant surfaces and a different era of patient expectations2,3,36,39. There was a time when patients were pleased simply to have a replacement tooth with less expectations of optimal esthetics or immediacy of return to function.

Prosthetically driven implant dentistry is a concept related to ideally placing dental implants in a 3D orientation for ideal esthetics and biomechanics based on a preview of the final prosthetic plan56,57. The transition from a surgically convenient implant placement to a prosthetically driven implant treatment plan has led to an increased need for accuracy in translation of pre-surgical planning to the surgical phase of implant therapy6,7,9,56,57. This need for improved accuracy in translation of planning to surgery, the desire to decrease morbidity and duration of surgical implant phases of 
treatment, and the desire for a more immediate return to function has led to the incorporation of digital technology into surgical armamentarium in the form of guided implant surgery6,9,13,14,16-18,23,26,30,31,33,56,58.

There are two main approaches to guided implant surgery in dentistry today. These are SLA 3D printed surgical guides with sleeves and computer guided navigation to guide the burs while drilling the osteotomy and while placing the implant7,13,14,16,17,20,23,26,30-33. There are a number of 3rd party services available for treatment planning and fabrication of static SLA guides available, however many dental implant therapy providers have adopted an in-house approach with treatment planning and fabrication of surgical guides on commercially available desktop 3D printers 33. Use of in office desktop 3D printing and treatment planning can make use of guided surgery more accessible at a lower cost than when purchased through 3rd party vendors29,33.

Computer guided navigation is a dynamic process involving fixation of a template to the patient prior to $\mathrm{CBCT}$ evaluation to relate the position of the patient to the treatment planning and navigation software25-28. This allows for a real time assessment and correction of the 3D position of the osteotomy bur or implant in relation to the planned position25-28. This dynamic navigation is newer technology in its application to dentistry than static surgical guides25-28. These products generally have a high initial cost of acquisition but have the benefit of not requiring additional materials to be placed in the surgical site that could interfere with access or limit irrigation of osteotomy burs25-28.

SLA 3D printed surgical guides use a printed resin structure to house a guiding sleeve through which the osteotomy bur is guided to the planned surgical site to control angle and depth13,16,17,20,21,30-33. There are 3 main supporting tissues available for static surgical guides. There are tooth supported guides, mucosa supported guides, bone supported guides $9,13,14,16-18,21,30,31$. Tooth supported guides are generally more accurate than either bone supported or mucosa supported guides. There is some disagreement among the literature as to whether bone supported or mucosa supported guides are more 
accurate, however mucosa supported guides are generally shown to be less accurate6,9,13,15-18,20,21,23,30-32,56,59-61.

Other factors that can affect the level of accuracy with which static surgical guides can transfer planned positions to the surgical procedure are whether the procedure is fully guided or partially guided and whether fixation pins are used or not15,20,23. A partially guided procedure is when the osteotomy is completed using the surgical guide but the implant is placed without the surgical guide15,23. A fully guided procedure is when both the osteotomy and implant placement are completed with the surgical guide in place15,23. While a partially guided procedure has a high degree of accuracy, less deviation from planned positions are seen when a fully guided procedure is utilized 15,23. Fixation pins are used to stabilize the position of static surgical guides and when utilized have been shown to significantly improve the accuracy of the surgical guide23. A recent systematic review and meta-analysis demonstrated the most accurate transfer of presurgical planned position to actual post-operative position was accomplished with a fully guided procedure with use of fixation pins23.

There is a body of literature supporting the improved ability to translate preoperative planned positions of dental implants to actual post-operative positions using guided implant surgery, whether with a static SLA guide or dynamic navigation, when compared to freehand implant surgery $15,25,59,60,62,63$. While no method of surgery is able to $100 \%$ accurately translate pre-operative planning to the surgical phase at this time, most authors report guided implant surgery can predictably result in a level of accuracy within $5^{\circ}$ of angular deviation and $2 \mathrm{~mm}$ of bodily $3 \mathrm{D}$ offset from planned position for both static and dynamic approaches6,9,13-18,20-23,25-28,30-32,55,56,59,60,62. Even with this level of accuracy when compared to conventional freehand surgery, the practitioner can expect an improvement in surgical and restorative outcomes of the dental implant treatment $6,9,18,55$. 


\section{Chapter III: MATERIALS AND METHODS}

\section{Project Overview}

This report is a presentation of interim data of an ongoing clinical study titled "Immediate Loading of 4 guided implants supporting a maxillary Overdenture using a Novaloc TiN retention system: Open ended prospective study." The primary aims of this study are to evaluate clinical and radiographic performance of 4 dental implants at 6 and 12 months following loading using a fully guided, flapless approach and an immediate loading protocol. Secondary aims are to evaluate implant survival at 6 and 12 months; the frequency and nature of prosthetic complications; patient centered outcomes using OHIP14 questionnaire; and the accuracy of the guided implant placement. The intent is to enroll 15-20 patients for a total of 60-80 implants for evaluation. The project started using $3.3 \mathrm{~mm}$ diameter Straumann (Straumann, Andover, MA) BLT implants. After the first 3 patients, materials were changed to using a $3.75 \mathrm{~mm}$ diameter Straumann BLX implant due to challenges in achieving high primary stability with BLT implants so only 2 patients receiving BLT implants will be included in this report. This report will focus on the assessment of surgical guide accuracy for the interim data collected as of May 2020.

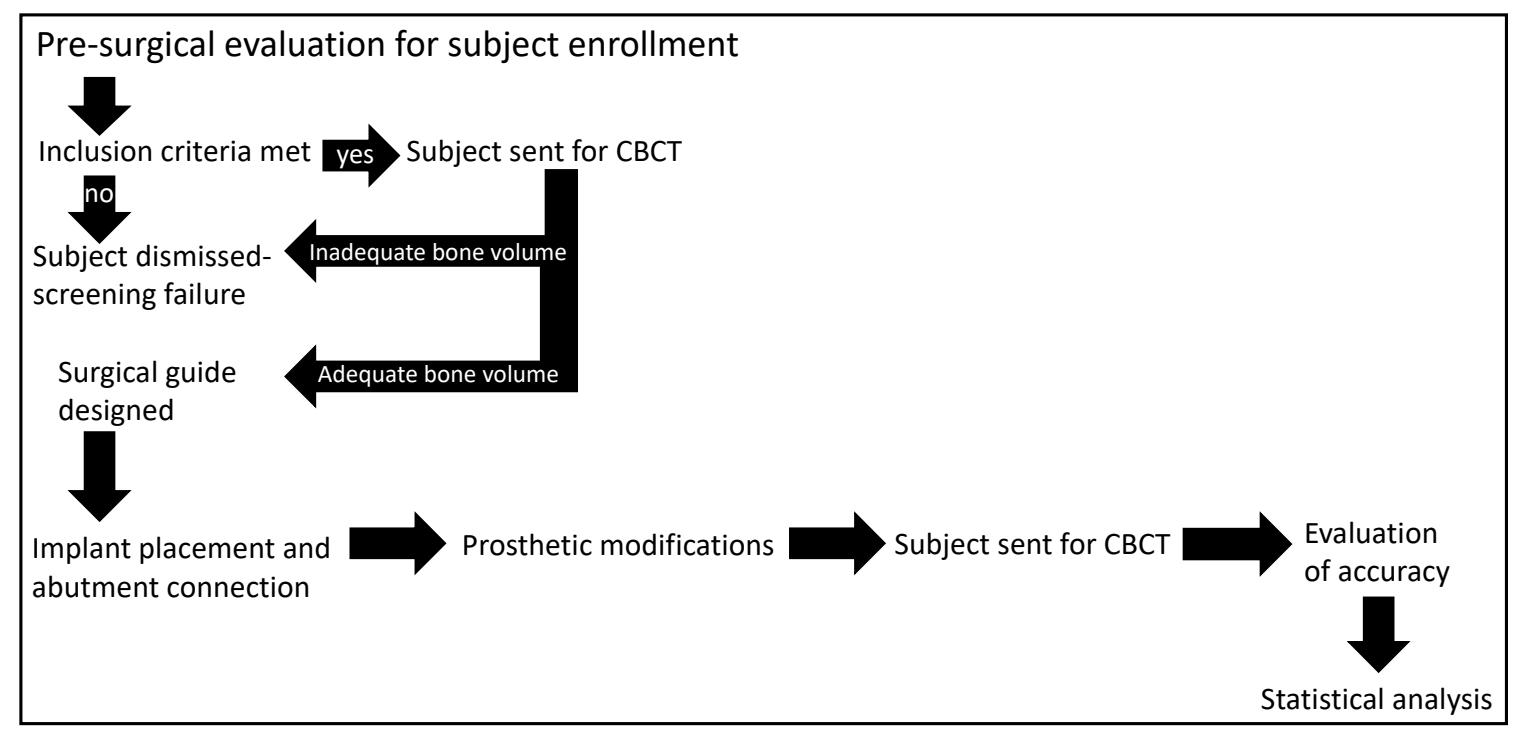

Figure 1. Flowchart of project workflow 


\section{Subject Enrollment}

The study protocol was approved by West Virginia University Office of Research Integrity and Compliance (IRB number 1801929813). Patients were enrolled at WVU School of Dentistry Departments of Graduate Periodontics and Prosthodontics. Subjects inclusion and exclusion criteria are presented in Table 1. Following the pre-screening visit if all inclusion criteria were met, informed consent was obtained. The patients were then sent for a dual scan CBCT to determine bone quality and quantity available for surgical implant placement. If the amount bone as evaluated on CBCT scan was not sufficient for appropriate planning, the patient was excluded from continuation of the study and listed as screening failure.

Table 1. Inclusion and exclusion criteria used during subject enrollment

\begin{tabular}{|c|c|}
\hline Inclusion Criteria & Exclusion Criteria \\
\hline Male or female at least 21 years of age & $\begin{array}{l}\text { Chronic condition requiring routine use of } \\
\text { prophylactic antibiotics prior to dental } \\
\text { procedures }\end{array}$ \\
\hline Fully edentulous Maxilla & $\begin{array}{l}\text { Chronic condition requiring prolonged use } \\
\text { of steroids }\end{array}$ \\
\hline $\begin{array}{l}\text { At least } 4 \text { months healing after most } \\
\text { recent Maxillary extractions }\end{array}$ & $\begin{array}{l}\text { History of leukocyte dysfunction or } \\
\text { deficiency }\end{array}$ \\
\hline $\begin{array}{l}\text { Existing Maxillary complete denture } \\
\text { deemed adequate by a Prosthodontist }\end{array}$ & Chronic bleeding disorder \\
\hline $\begin{array}{l}\text { Adequate bone in at least } 2 \text { nd premolar } \\
\text { area of Maxilla to house dental implant }\end{array}$ & $\begin{array}{l}\text { History of neoplasm requiring radiation or } \\
\text { chemotherapy in region }\end{array}$ \\
\hline No bone grafting required & Metabolic bone disorder \\
\hline \multirow{6}{*}{$\begin{array}{l}\text { Insertion torque of at least } 20 \mathrm{Ncm} \text { to } \\
\text { immediately load }\end{array}$} & Uncontrolled endocrine disorder \\
\hline & $\begin{array}{l}\text { Use of investigational drug or device } \\
\text { within } 30 \text { days of implant surgery }\end{array}$ \\
\hline & Smoking greater than 10 cigarettes \\
\hline & Alcohol or drug abuse \\
\hline & HIV infection \\
\hline & $\begin{array}{l}\text { Condition or circumstances, in the opinion } \\
\text { of the investigator, which would prevent }\end{array}$ \\
\hline
\end{tabular}




\begin{tabular}{|l|}
\hline $\begin{array}{l}\text { completion of study participation or } \\
\text { interfere with analysis of study results, } \\
\text { such as history of non-compliance, } \\
\text { unreliability. }\end{array}$ \\
\hline $\begin{array}{l}\text { Local inflammation including untreated } \\
\text { periodontitis }\end{array}$ \\
\hline Mucosal disease such as lichen planus \\
\hline History of local radiation therapy \\
\hline Osseous lesion \\
\hline Severe bruxism and clenching habits \\
\hline $\begin{array}{l}\text { Active infection with suppuration or } \\
\text { draining fistula }\end{array}$ \\
\hline Persistent intraoral infection \\
\hline $\begin{array}{l}\text { Lack of insertion torque of at least } 20 \mathrm{Ncm} \\
\text { for immediate loading. If so, patient to be } \\
\text { treated following delayed loading protocol }\end{array}$ \\
\hline Inadequate oral hygiene or home care \\
\hline Bone grafting required \\
\hline
\end{tabular}

The dual scan CBCTs were merged in coDiagnostiX (DentalWings, Montreal, Canada) to evaluate bone available for surgical implant placement. 4 dental implants were planned in roughly residual sites \#4, \#7, \#10, and \#13. Three fixation pins were planned for each patient. Sleeve height setting was selected at the lowest sleeve height setting that would allow the majority of the apical aspect of the guide sleeve to be above the soft tissue. Dental implant placement, fixation pin placement, and sleeve height setting were approved by a Periodontist and a Prosthodontist. Surgical guides were designed using the existing complete denture including the occlusal surfaces as the stent and incorporating the guide sleeves into the stent (see Figure 2). A stl file of the surgical guide was the exported from coDiagnostiX and 3D printed on a Form 2 (Formlabs, Somerville, MA) desktop 3D printer using DentalSG resin (Formlabs, 
Somerville, MA). Post processing was completed per manufacturer's instructions.

Surgical guides were cold sterilized prior to use in dental implant surgery.

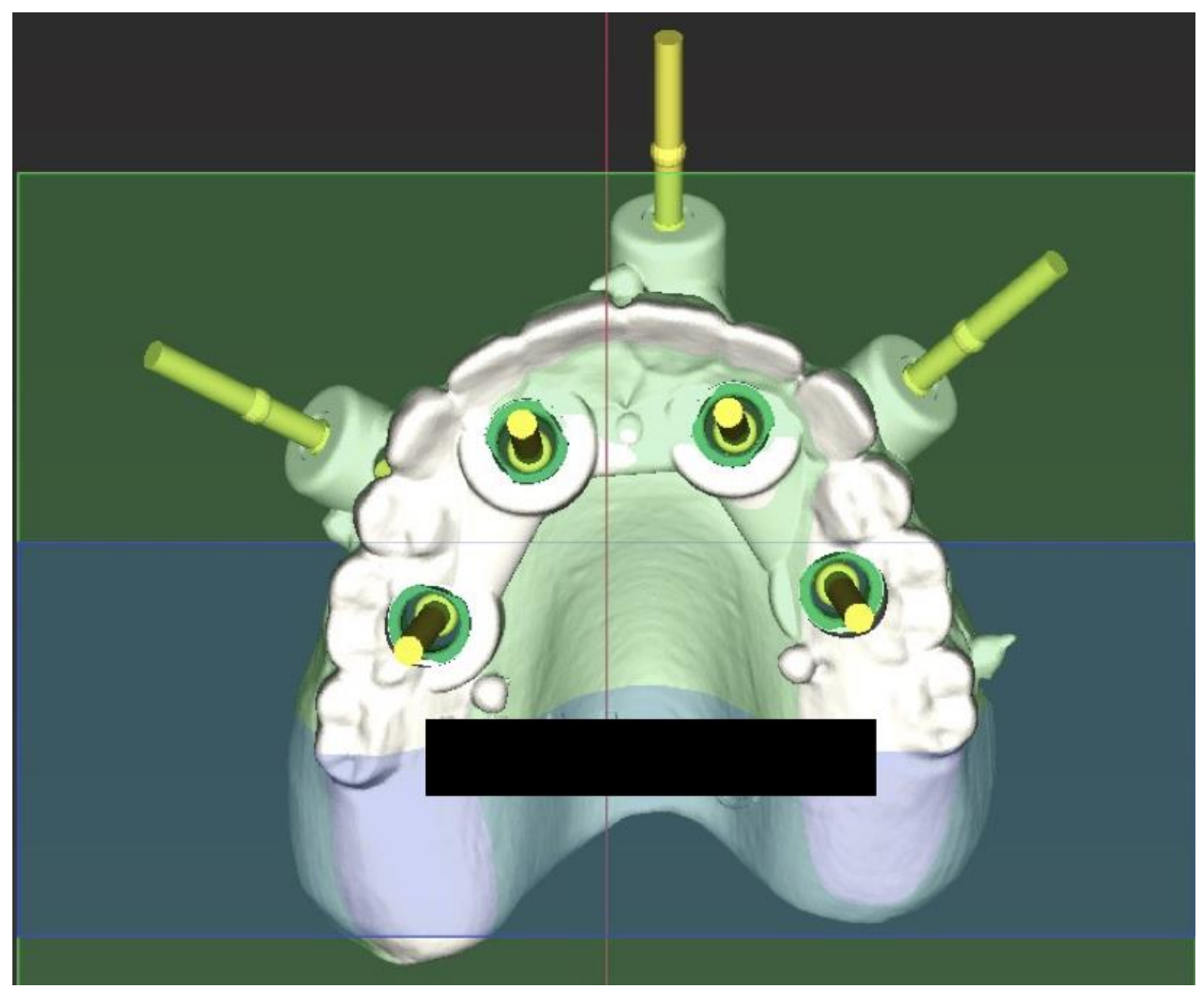

Figure 2. Occlusal view of example surgical guide design incorporating guide sleeves and fixation pin sleeves into duplicate of existing complete denture.

\section{Surgical and Prosthetic Procedures}

Upon presentation, patients were given a prophylactic dose of $2 \mathrm{~g}$ Amoxicillin or $600 \mathrm{mg}$ Clindamycin if allergic to Amoxicillin. Surgical guide was tried in to evaluate fit and occlusion. Occlusal seating index was made for each patient using Regisil PB (Dentsply Sirona, Charlotte, NC) to aid in repositioning to ensure repeatable seating for fixation pin placement. Implant sites were prepared per manufacturer's instructions for a fully guided, flapless approach and were placed through the surgical guide. Insertion torque was recorded for each implant. 2 patients received $3.3 \mathrm{~mm}$ BLT implants and 7 patients received 3.75 BLX implants. 
Once all 4 implants were placed, the soft tissue cuff was measured and the appropriate abutment was placed. For the 2 patients that received the $3.3 \mathrm{~mm}$ BLT implants, the appropriate height of NC Locator abutment (Zest Anchors, Escondido, CA) was selected and placed to $15 \mathrm{Ncm}$. Of the 7 patients that received the $3.75 \mathrm{BLX}$ implants, 2 patients received appropriate height of healing abutment due to an insertion torque of less than $20 \mathrm{Ncm}$ in at least 1 of the 4 implants and 5 received the appropriate height and angle of RB Novaloc abutment (Straumann, Andover, MA) torqued to $15 \mathrm{Ncm}$.

Dentures were relieved and relined with Coe-Soft (GC America, Alsip, IL) per manufacturer's instructions for the 2 patients who received healing abutments. Dentures were relieved and Locator housings (Zest Anchors, Escondido, CA) were picked up in prosthesis per manufacturer's instructions using BosWorth TruRepair (Keystone Industries, Gibbstown, NJ) for patients who received NC Locator abutments on $3.3 \mathrm{~mm}$ BLT implants (see Figure 3). Dentures were relieved and Novaloc housings (Straumann, Andover, MA) were picked up in prosthesis per manufacturer's instructions using BosWorth TruRepair for patients who received RB Novaloc abutments on $3.75 \mathrm{~mm}$ BLX implants. All patients were instructed to wear their Mx prosthesis 24 hours a day without removal for 1 week. 

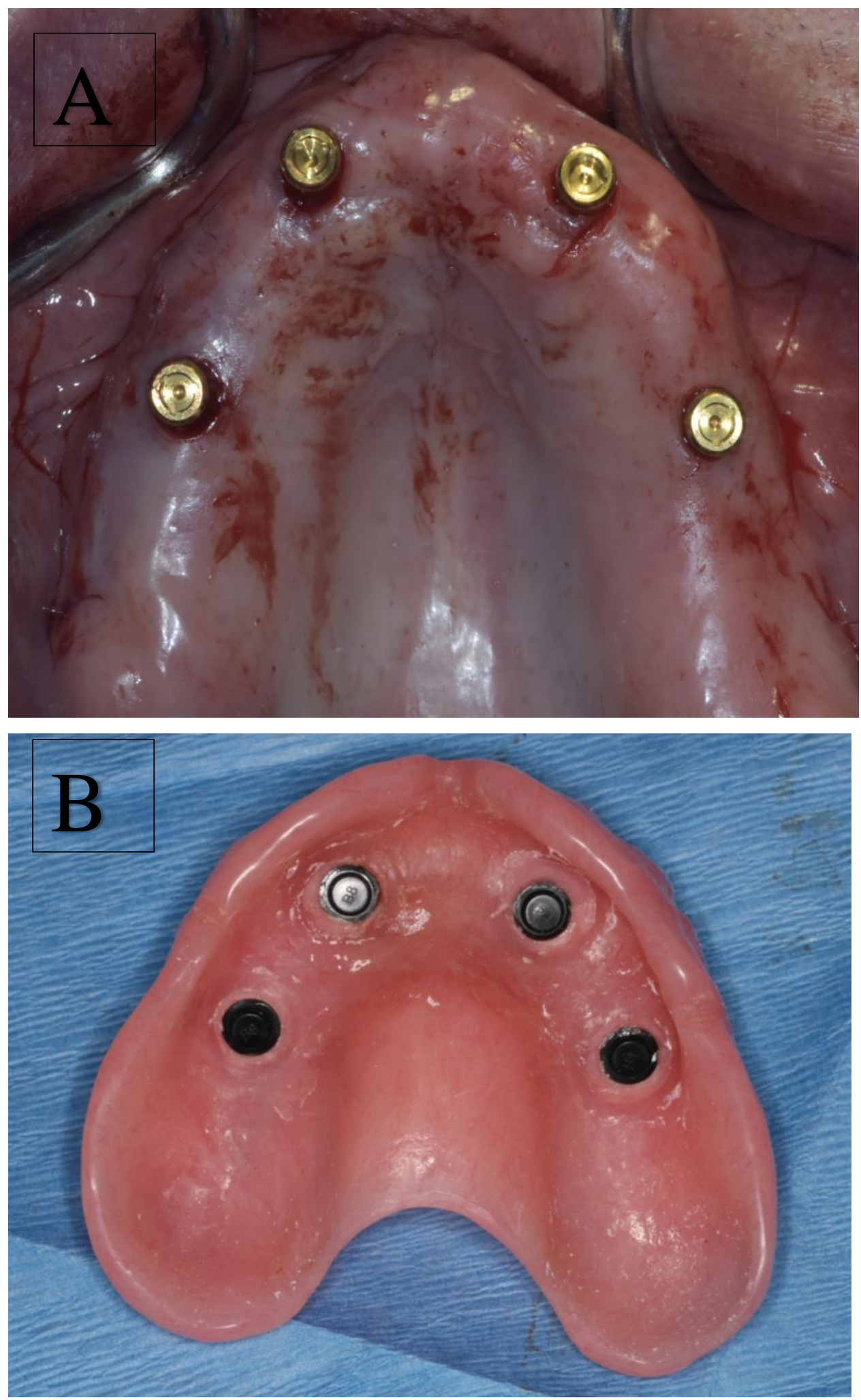

Figure 3 A and B. A. Immediate post-operative occlusal view of example patient following implant and abutment placement. B. Immediate post-operative view of intaglio of Maxillary prosthesis following housing pick up for the same example patient. 


\section{Post-operative Assessment}

At the 1-year post-operative follow up visit, a post-operative CBCT was obtained to reflect the protocol established in the initial IRB approval. In addition to updates to the IRB protocol with the regard to change of materials with BLX implants, BLX group patients were sent for post-operative CBCT scans immediately following implant placement.

\section{Statistical Analysis}

Post-operative CBCTs were imported into coDiagnostiX to be compared with preoperative plans. Data were segmented and overlapped to allow for 3D analysis in the Treatment Evaluation module. Once data sets were overlapped, the planned implant was manually adjusted to overlap the radiographic display of the actual implant position. The software then generated the error values and displayed the images of the overlap (see Figure 4).
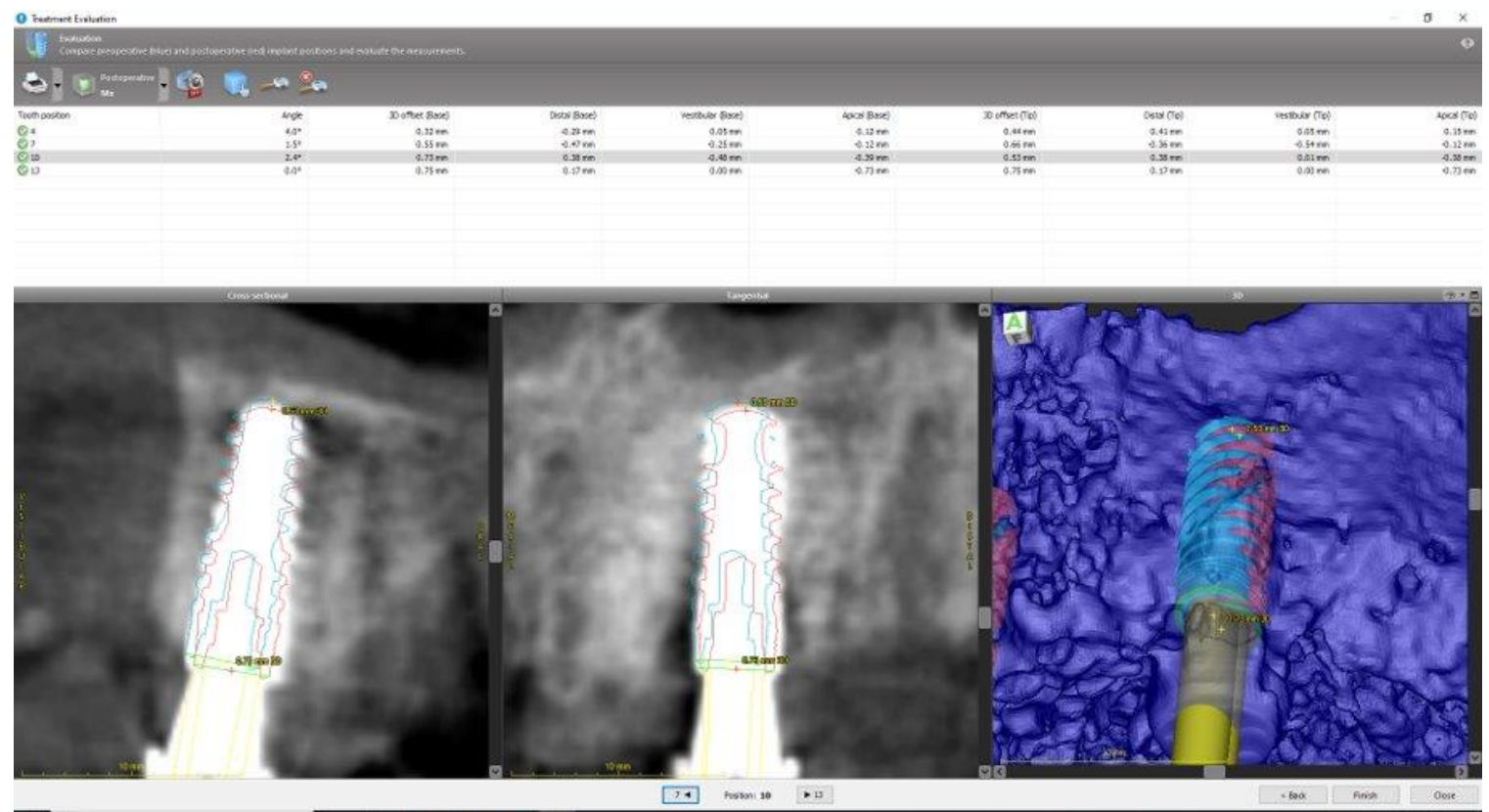

Figure 4. Example display of error values and display of pre-operative "planned" implant position displayed in blue and post-operative "actual" implant position displayed in red.

Data were collected and recorded in an Excel (Microsoft, Redmond, WA) spreadsheet, and a mean and range was determined for the whole dataset for angular 
deviation and 3D offset at base and tip of implants. Kolmogorov-Smirnov tests were conducted to confirm a normal distribution of the dataset. Sleeve height settings were analyzed by One-Way ANOVA analysis for angular deviation and 3D offset at base and tip of each implant site. A series of T-tests were conducted to evaluated angular deviation and 3D offset at base and tip of each implant site with regard to implant design (BLT vs BLX) and location in maxillary arch (anterior vs posterior). 


\section{Chapter IV}

\section{Results}

Nine patients, 8 males and 1 female were included in this report. The average age was 63.3 years with a range of 51-73 years Two patients received $3.3 \mathrm{~mm}$ BLT implants and 7 patients received 3.75 BLX implants. See Table 2 for a description of implant design, length, and distribution for the enrolled subjects. A total of 34 implants were available for evaluation. Of the 2 patients that received BLT implants, 1 implant failed during the 12 month follow up resulting in 7 implant sites available for statistical evaluation. Of the 7 patients that received BLX implants, 1 implant was mis-directed during placement and a new site was prepared and received an implant in a free-hand fashion resulting in 27 implant sites available for statistical analysis. KolmogorovSmirnov tests demonstrated that all data subsets analyzed were normally distributed.

Table 2. Patient Demographics and implant distribution based on length and design.

\begin{tabular}{|r|c|c|}
\hline Implant design & BLT & BLX \\
\hline Number of patients & 2 & 7 \\
\hline Number of males & 2 & 6 \\
\hline Number of females & 0 & 1 \\
\hline Mean age & 68 & 62 \\
\hline Number of implant & 7 & 27 \\
\hline sites & & \\
\hline Implant length $\mathbf{1 0} \mathbf{~ m m}$ & 5 & 8 \\
\hline Implant length $\mathbf{1 2} \mathbf{~ m m}$ & 2 & 19 \\
\hline
\end{tabular}

The mean angular deviation of all implant sites evaluated was $3.0^{\circ}$ with a range of $0.0^{\circ}-6.9^{\circ}$ (see Table 3). The mean 3D offset at the base of the implant, the implant platform, was $1.05 \mathrm{~mm}$ with a range of $0.26 \mathrm{~mm}-2.32 \mathrm{~mm}$ (see Table 3). The mean 3D 
offset at the tip of the implant, the implant apex, was $1.1 \mathrm{~mm}$ with a range of $0.26 \mathrm{~mm}-$ $2.54 \mathrm{~mm}$ (see Table 3).

Table 3. Angular deviation and 3D offset of actual implant position compared to planned position.

\begin{tabular}{|c|c|c|c|}
\hline & $\begin{array}{c}\text { Angular } \\
\text { Deviation }\left(^{\circ}\right)\end{array}$ & $\begin{array}{c}\text { 3D offset- base } \\
(\mathbf{m m})\end{array}$ & $\begin{array}{c}\text { 3D offset- tip } \\
(\mathbf{m m})\end{array}$ \\
\hline $\begin{array}{c}\text { Mean } \\
\text { (+/- SD) }\end{array}$ & $3.0(1.68)$ & $1.05(0.57)$ & $1.1(0.61)$ \\
\hline Range & $0.0-6.9$ & $0.26-2.32$ & $0.26-2.54$ \\
\hline $\mathbf{n}$ & 34 & 34 & 34 \\
\hline
\end{tabular}

When data were stratified for sleeve height setting, there were no significant differences between sleeve height settings H2, H4, or H6 (see table 4 and Figures 4-6). Mean angular deviations for sleeve height settings $\mathrm{H} 2, \mathrm{H} 4$, and $\mathrm{H} 6$ were $2.58^{\circ}, 3.11^{\circ}$, and $2.88^{\circ}$ respectively (see Figure 5). Mean 3D offset at the base of the implant, the implant platform, for sleeve height settings $\mathrm{H} 2, \mathrm{H} 4$, and $\mathrm{H} 6$ were $0.83 \mathrm{~mm}, 1.08 \mathrm{~mm}$, and 1.09 mm respectively (see Figure 6). Mean 3D offset at the tip of the implant, the implant apex, for sleeve height settings $\mathrm{H} 2, \mathrm{H} 4$, and $\mathrm{H} 6$ were $1.01 \mathrm{~mm}, 1.20 \mathrm{~mm}$, and $1.02 \mathrm{~mm}$ respectively (see Figure 7). Results of 1-way ANOVA for each aspect under investigation demonstrated no significant differences at $\alpha=0.05$.

Table 4. Mean angular deviation and 3D offset of actual implant position compared to planned position for different sleeve height settings.

\begin{tabular}{|l|l|l|l|l|}
\hline $\begin{array}{l}\text { Sleeve height } \\
\text { setting }\end{array}$ & $\begin{array}{l}\text { Angular Deviation } \\
\left({ }^{\circ}\right)\end{array}$ & $\begin{array}{l}\text { 3D offset- base } \\
(\mathbf{m m})\end{array}$ & $\begin{array}{l}\text { 3D offset- tip } \\
(\mathbf{m m})\end{array}$ & $\mathbf{n}$ \\
\hline $\mathrm{H} 2$ & 2.58 & 0.83 & 1.01 & 5 \\
\hline H4 & 3.11 & 1.08 & 1.20 & 17 \\
\hline H6 & 2.88 & 1.09 & 1.02 & 12 \\
\hline
\end{tabular}




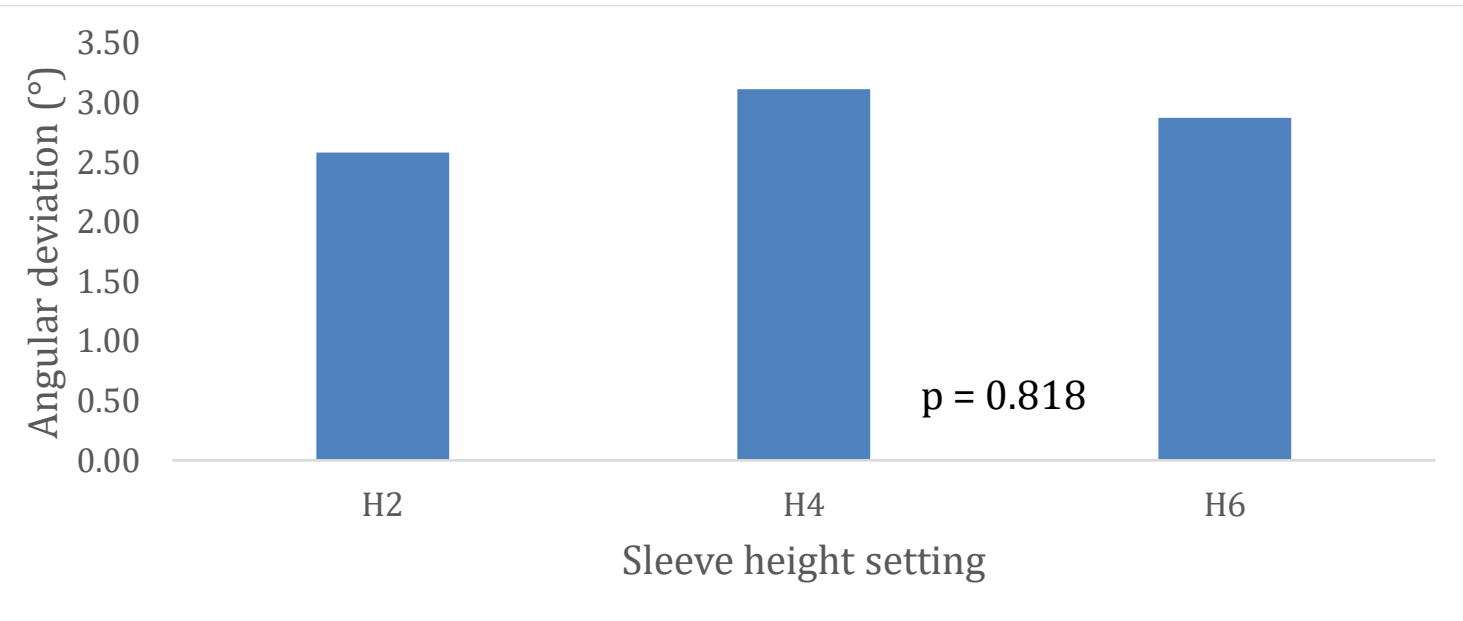

Figure 5. Comparison of mean angular deviation of actual implant position compared to planned implant position between different sleeve heights. (ANOVA)

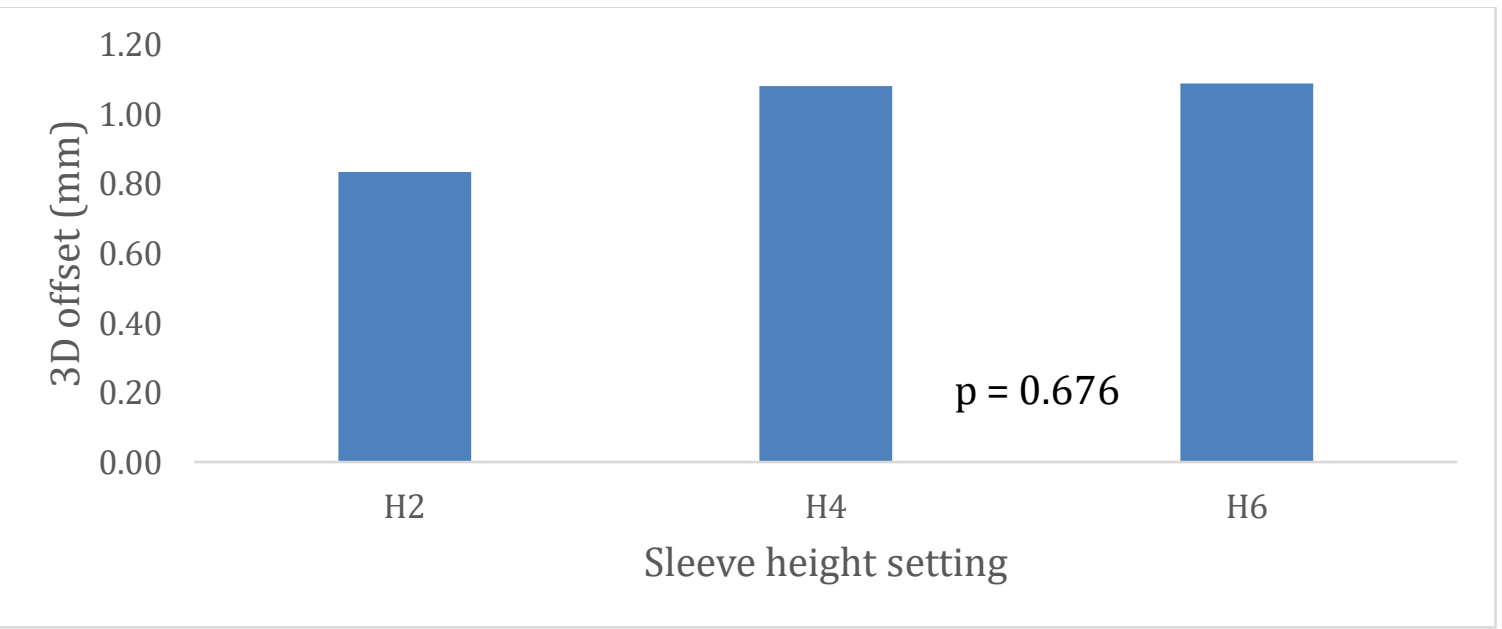

Figure 6. Comparison of mean 3D offset at base of actual implant position compared to planned implant position between different sleeve height settings. (ANOVA) 


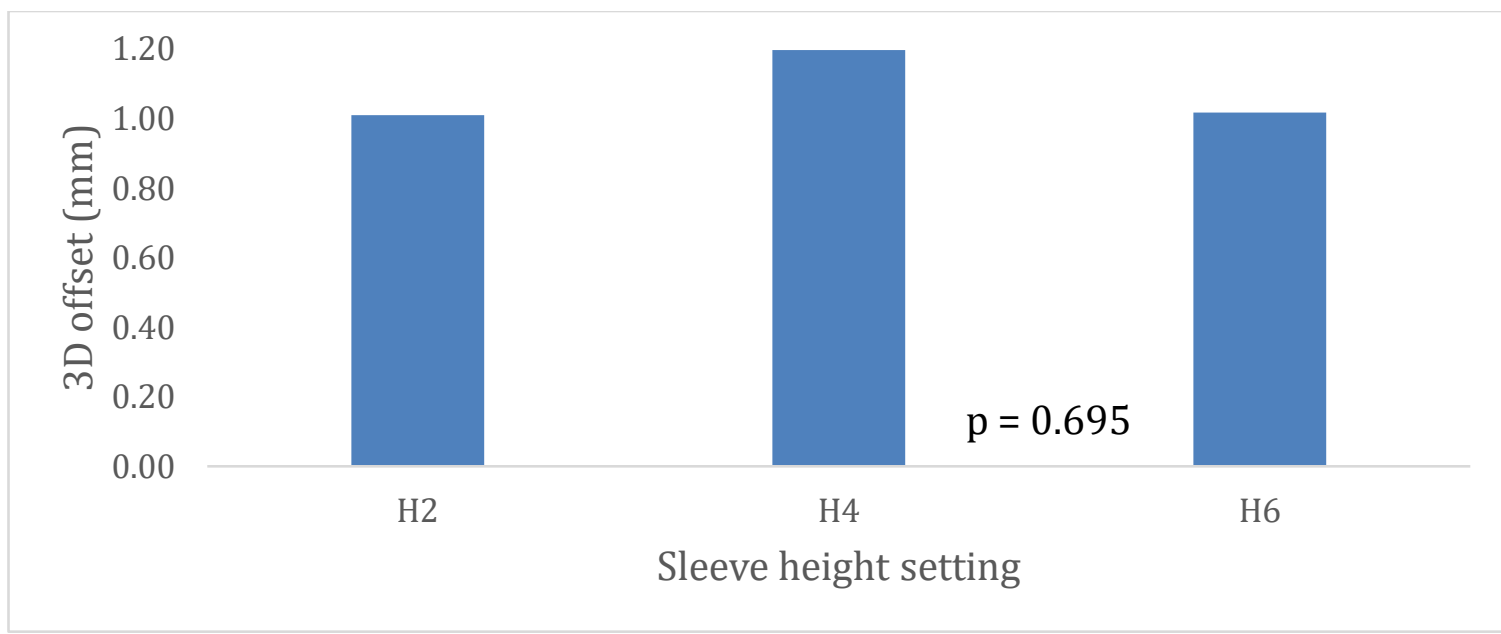

Figure 7. Comparison of mean 3D offset at tip of actual implant position compared to planned implant position between different sleeve height settings. (ANOVA)

When data were stratified based on implant design utilized, results showed a significant differences between the groups with regard to 3D offset at the base of the implant, but no significant differences were found for angular deviation or 3D offset at the tip of the implant (see Table 5 and Figures 7-9). Mean angular deviations were $2.1^{\circ}$ for BLT group and $3.2^{\circ}$ for BLX group with no significant differences seen between the means of the 2 designs (see Figure 8). A significant difference $(p=0.015)$ between 3D offset at the base of the implant, the implant platform, was seen with a mean of $1.46 \mathrm{~mm}$ for BLT group and $0.94 \mathrm{~mm}$ for BLX group (see Figure 9). No significant difference was seen for mean 3D offset at the tip of the implant, the implant apex, between the BLT and BLX group, p-value ( $\mathrm{p}=0.056$ ) (Fee Figure 10). Means of $1.43 \mathrm{~mm}$ and $1.02 \mathrm{~mm}$ were found for BLT and BLX groups respectively.

Table 5. Mean angular deviation and 3D offset of actual implant position compared to planned position for different implant designs. (*indicates $\mathrm{p}<0.05$ in Student T-test)

\begin{tabular}{|c|c|c|c|c|}
\hline $\begin{array}{c}\text { Implant } \\
\text { system }\end{array}$ & $\begin{array}{c}\text { Mean Angular } \\
\text { Deviation }\left(^{\circ}\right)\end{array}$ & $\begin{array}{c}\text { 3D offset- base } \\
(\mathbf{m m})\end{array}$ & $\begin{array}{c}\text { 3D offset- tip } \\
(\mathbf{m m})\end{array}$ & $\mathbf{n}$ \\
\hline BLT & 2.1 & $1.46^{*}$ & 1.43 & 7 \\
\hline BLX & 3.2 & $0.94^{*}$ & 1.02 & 27 \\
\hline
\end{tabular}




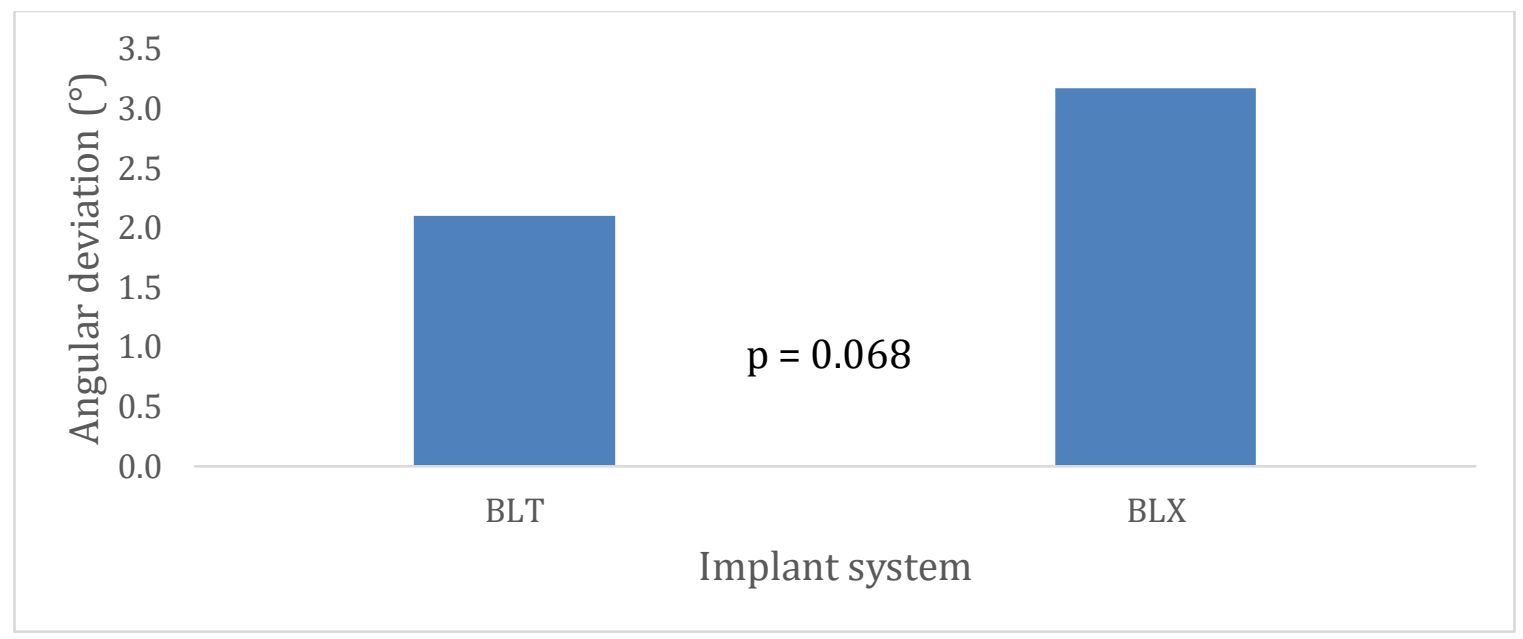

Figure 8. Comparison of mean angular deviation of actual implant position compared to planned implant position between implant designs. (Student t-test)

$$
\begin{aligned}
& 1.60 \\
& 1.40 \\
& \text { छ } 1.20 \\
& \text { छ्छ } 1.00 \\
& \text { ๑ } 0.80
\end{aligned}
$$

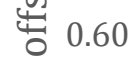

$$
\begin{aligned}
& \text { ले } 0.40 \\
& 0.20 \\
& 0.00
\end{aligned}
$$

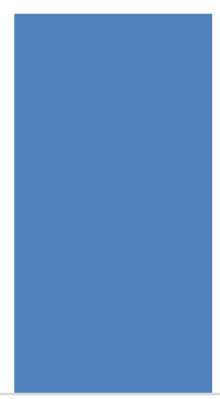

BLT

$$
\mathrm{p}=0.015
$$

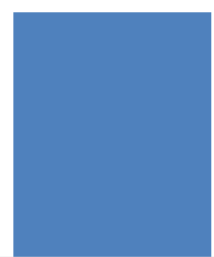

BLX

Implant system

Figure 9. Comparison of mean 3D offset at base of actual implant position compared to planned implant position between different implant designs. (Student t-test) 


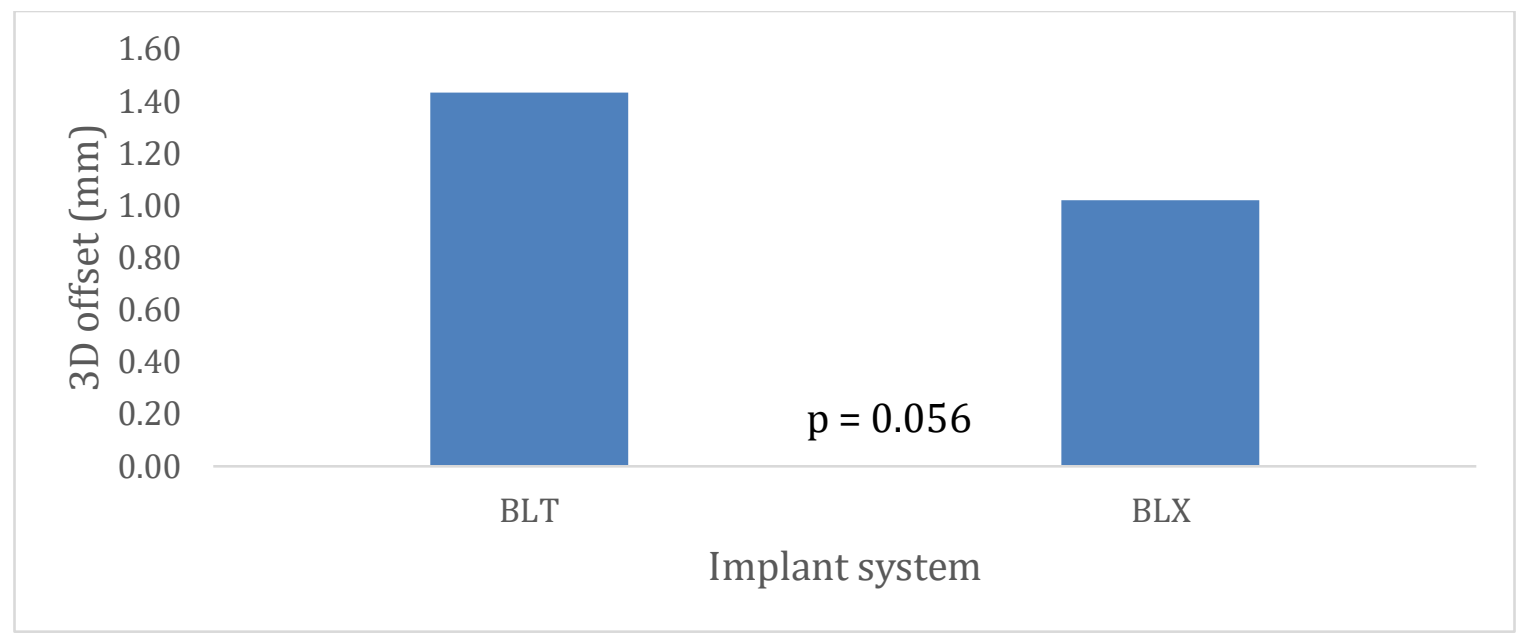

Figure 10. Comparison of mean 3D offset at tip of actual implant position compared to planned implant position between different implant designs. (Student t-test)

Further investigation demonstrated a significant difference in 3D offset when comparing implants placed in anterior regions of the maxilla to implants placed in posterior regions of the maxilla but no differences were seen for angular deviation (see Table 6 and Figures 10-12). Mean angular deviations were $2.57^{\circ}$ for anterior implants and $3.33^{\circ}$ for posterior implants (see Figure 11). Mean 3D offset at the base of the implant, the implant platform, were $0.92 \mathrm{~mm}$ for anterior implants and $1.18 \mathrm{~mm}$ for posterior implants (see Figure 12). A significant difference $(p=0.035)$ between 3D offset at the tip of the implant, the implant apex, was seen with a mean of $0.92 \mathrm{~mm}$ for anterior implants and $1.30 \mathrm{~mm}$ for posterior implants (see Figure 13).

Table 6. Mean angular deviation and 3D offset of actual implant position compared to planned position for different implant locations. (*indicates $\mathrm{p}<0.05$ in Student t-test)

\begin{tabular}{|c|c|c|c|c|}
\hline $\begin{array}{c}\text { Implant } \\
\text { location }\end{array}$ & $\begin{array}{c}\text { Angular Deviation } \\
\left({ }^{\circ}\right)\end{array}$ & $\begin{array}{c}\text { 3D offset- base } \\
(\mathbf{m m})\end{array}$ & $\begin{array}{c}\text { 3D offset- tip } \\
(\mathbf{m m})\end{array}$ & $\mathbf{n}$ \\
\hline Anterior & 2.57 & 0.92 & $0.92 *$ & 17 \\
\hline Posterior & 3.33 & 1.18 & $1.30 *$ & 17 \\
\hline
\end{tabular}




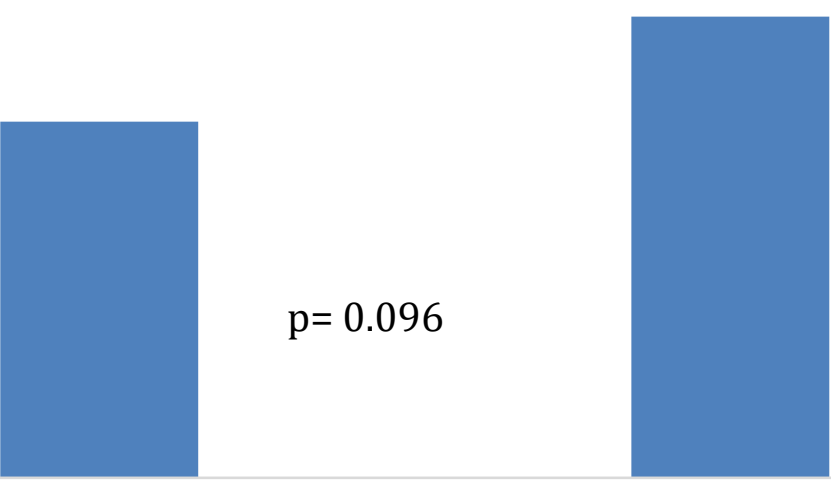

Anterior

Posterior

Implant location

Figure 11. Comparison of mean angular deviation of actual implant position compared to planned implant position between different implant locations. (Student t-test)

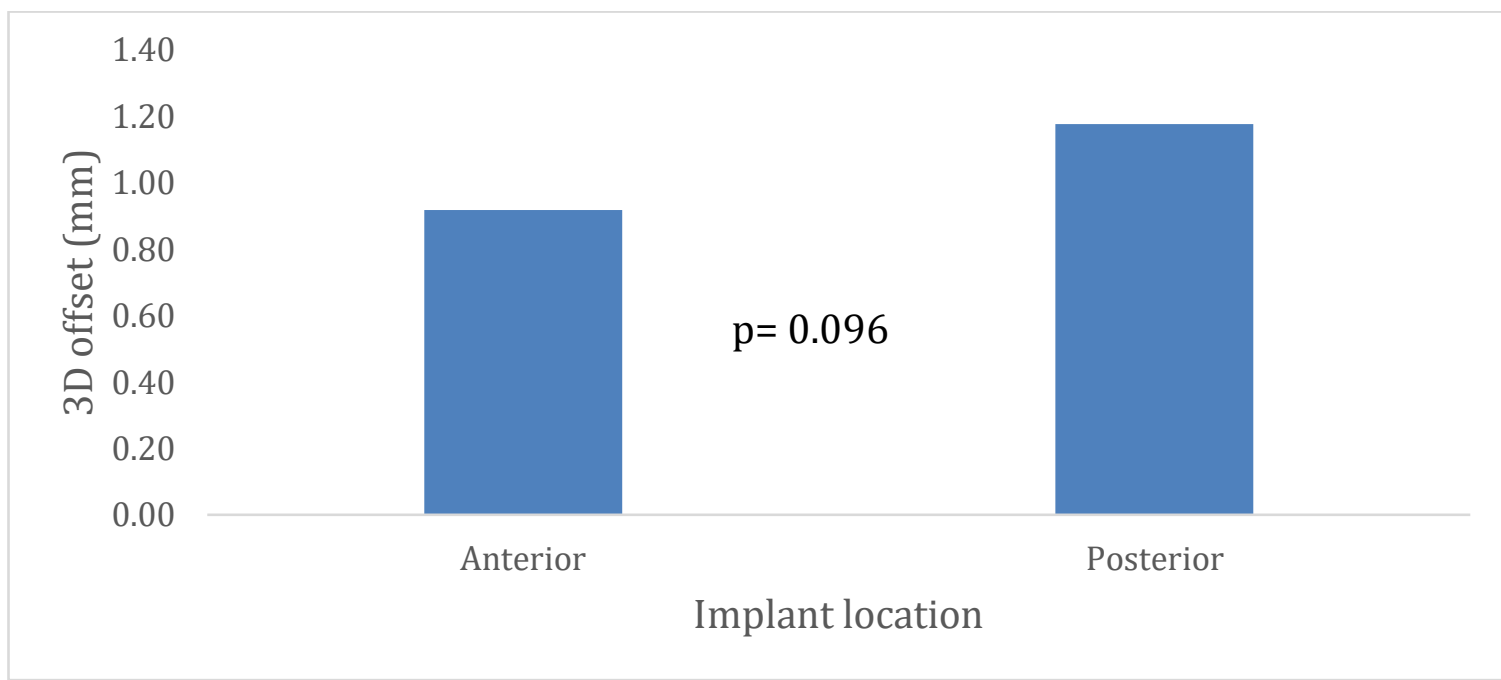

Figure 12. Comparison of mean 3D offset at base of actual implant position compared to planned implant position between different implant locations. (Student t-test) 


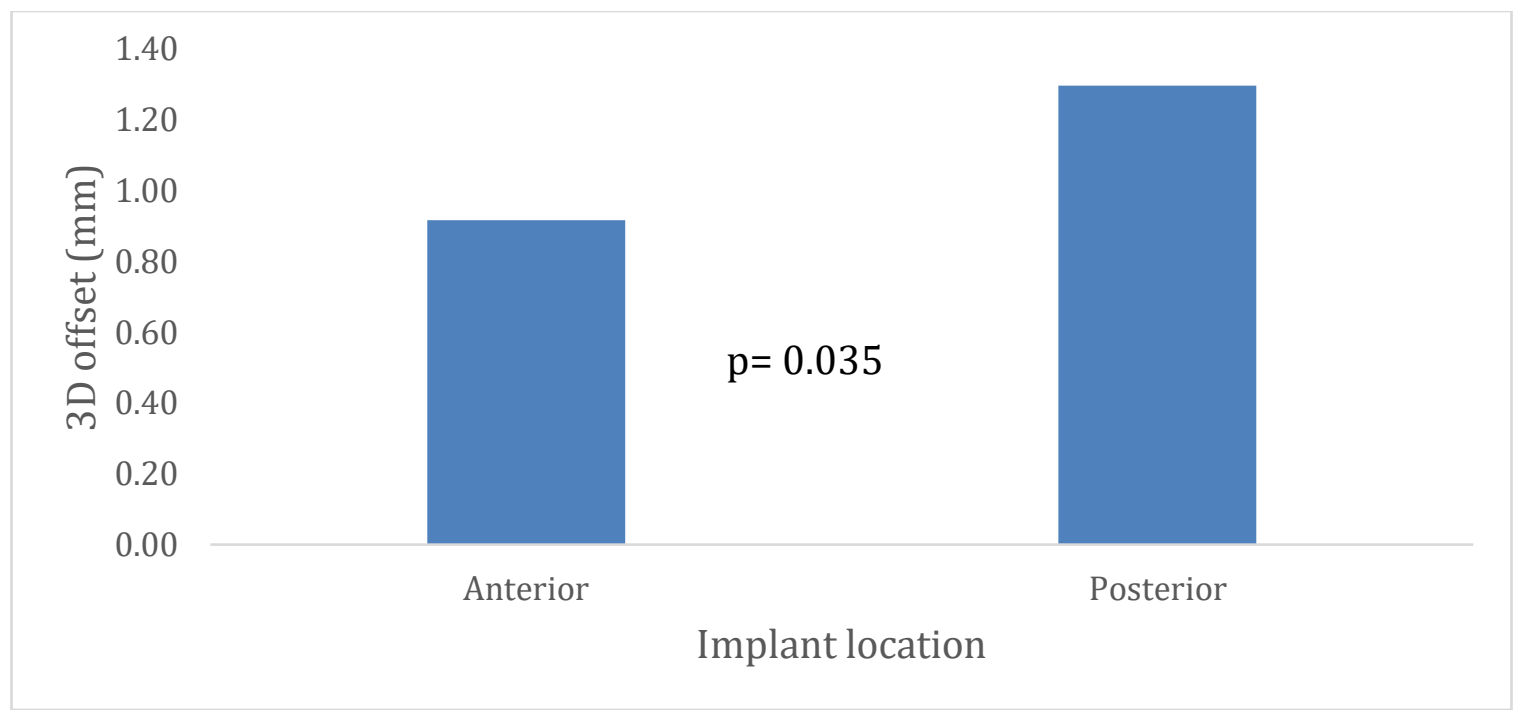

Figure 13. Comparison of mean 3D offset at tip of actual implant position compared to planned implant position between different implant locations. (Student t-test)

\section{Discussion}

In this study, a fully guided implant placement with a flapless approach using fixation pins showed $3.0^{\circ}$ of angular deviation and $1.05 \mathrm{~mm}$ to $1.1 \mathrm{~mm}$ of bodily deviation at the platform and apex respectively. A recent systematic review and metaanalysis reported an angular deviation of $4.1^{\circ}$ and $1.25 \mathrm{~mm}$ deviation at the implant platform and $1.57 \mathrm{~mm}$ deviation at the implant apex23. This same meta-analysis also demonstrated that a fully guided surgery with a flapless approach using a guide with fixation pins resulted in the most accurate application of the pre-surgical plan to the surgical phase of the implant treatment23. A recent clinical study reported use of the same implant treatment planning and treatment evaluation software to evaluate the accuracy of BLT implants using a mucosa supported guide without fixation pin use and found a slightly higher level of inaccuracy than this study at $4.89^{\circ}$ of angular deviation and 1.60 $\mathrm{mm}$ and $1.86 \mathrm{~mm}$ of bodily deviation at the platform and apex respectively6. These findings further support the findings of Zhou et al. that the use of fixation pins improves accuracy of guided implant surgery in the edentulous arch23.

The fact that there was no difference in accuracy between any of the sleeve heights is in contrast to previous reports which demonstrated increased potential for inaccuracy as distance from planned implant platform to the top of the guided sleeve 22. 
Multiple reports have demonstrated that greater the distance from the bone, the more potential for deviation exists 15,16,22,31. This greater potential for deviation is due to the tolerances of movement within the surgical guide sleeve that allows for some eccentric movements resulting in a cone of error with the tip at the top of the sleeve that widens as the distance to the bone is increased22. It has also been reported that increased levels of mucosa thickness resulted in greater levels of inaccuracies13,16,22. This could be due to the increased resiliency of the thicker tissue than can allow for more movement of the guide13,16,22,24. In our protocol it can be assumed that an H6 sleeve height setting corresponded to an increased soft tissue thickness as the technique for sleeve height selection was based on having the majority of the apical aspect of the sleeve above the tissue since bone level implants were planned at or slightly below the boney crest. A possible explanation for the lack of difference could be the fact that the surgical protocol included a fully guided surgery with a flapless approach with fixation pins which has been shown to improve the accuracy of guided implant surgery 23

While the only statistically significant difference between the $3.3 \mathrm{~mm}$ BLT implant and the $3.75 \mathrm{~mm}$ BLX implant was seen in 3D offset at the level of the implant platform with a greater degree of error seen in the $3.3 \mathrm{~mm}$ BLT implant, the difference between mean 3D offset at the tip of the two different designs was borderline. It is unclear at this point if the difference will be significant once additional data to be collected is analyzed. The significant difference seen in the $3 \mathrm{D}$ offset of the two implant systems could be explained partially by the more aggressive threads and design of the BLX implant allowing for a level of self-drilling not capable of the BLT implant51. The BLX implant's drilling protocol is based on the bone type and allows for variations in drilling protocols for the implant osteotomy based on the tactile sensation of the density of the bone51. This would allow for an undersized osteotomy preparation to achieve an increased level of initial stability without sacrificing accuracy of placement51. If the treatment plan includes immediately loading the implants, then a high degree of initial stability is desired to allow the prosthetic connection to safely proceed without additional risk of micromovement that could cause a lack of osseointegration compromising the overall outcome of the treatment3-5,7,14,40,41. 
These results are consistent recent reports evaluating accuracy of guided surgery which found an increased likelihood of discrepancy for implants placed in posterior areas when compared to anterior areas6,64,65. Vasak et al. demonstrated a significantly increase level of inaccuracy for guided implants placed in the posterior regions and in the maxilla using NobelGuide64. It was also found that 3D offset and angular deviation of guided implants in posterior sites could be almost double that of implants placed with the same guide in a more anterior region65. The difference in accuracy of dental implants placed in the anterior maxilla compared to the posterior maxilla could be due to a number of factors. One potential factor could be due to the softer bone quality typically seen in the posterior maxilla compared to the anterior maxilla that could allow the implant to redirect itself more during placement in softer bone than in the denser bone38. Another factor that could have led to the increase inaccuracy in the posterior regions is due to the design of the surgical guides. A similar design was used for all guides in which 3 fixation pins were used with 1 pin placed just left or right of midline and the other 2 pins placed between the anterior and posterior implant sites (see Figure 1). This may have allowed for greater stability in the anterior region while there could have been more displacement of the posterior segments as the osteotomies were being drilled. Further investigation into accuracy of dental implants placed using guides with fixation pins with regard to distance of distal sites from fixation pins as well as angle between the posterior two fixation pins is warranted.

Some of the limitations of this study include that the data analyzed and reported are interim data of an ongoing prospective clinical trial, and thus the case numbers are limited. Once all subjects have been treated and data can be analyzed it is unclear if a clinically significant effect will accompany the statistically significant differences seen in this interim report. Another potential factor that limits the generalizability of these data are that the analyses comparing the BLT implant design to the BLX implant was quasi retrospective in nature as patients were not randomly allocated to receive either BLT or BLX. The analysis simply compared the data collected of the two groups following 
collection. With a difference of $0.52 \mathrm{~mm}$ as seen in this study, a clinically significant impact of the error is unlikely.

While there were some statistically significant differences seen in the dataset, the likelihood of a $1 \mathrm{~mm}$ deviation from planned position causing a clinically relevant problem is low, especially in this protocol in which a removable restorative solution was utilized. If a fixed solution was the planned treatment, there is less room for error in accuracy of placement as a fixed solution requires a screw access channel7,9,14,18. If inaccuracies resulted in a screw access position that was too facial or too buccal then these complicating factors could result in an esthetic compromise or a functional compromise with screw accesses being visible or veneering porcelains to be unsupported due to positioning. Further investigation into methods of reducing inaccuracies between pre-surgical planning and post-operative implant positions is warranted. 


\section{Chapter V: Summary and Conclusion}

\section{Summary}

This study evaluated Straumann BLT and BLX implants placed using a fully guided, flapless approach with a mucosa supported SLA surgical guide with 3 fixation pins. Accuracy of actual implant positions were compared to the pre-surgical plan using a Treatment Evaluation module in the coDiagnostiX software with regard to angular deviation and 3D offset at the base and the tip of the implants. An average angular deviation of $3.0^{\circ}$ was seen. An average $3 \mathrm{D}$ offset of $1.05 \mathrm{~mm}$ and $1.10 \mathrm{~mm}$ were seen at the base and tip of the implants respectively. A statistically significant difference was seen between BLT and BLX implants with respect to 3D offset at the level of the implant platform. A statistically significant increase in average 3D offset at the tip of implants were seen in implants placed in posterior regions when compared to anterior regions.

\section{Conclusion}

1) A fully guided, flapless approach with a mucosa supported SLA surgical guide with 3 fixation pins using Straumann BLT or BLX implants can be expected to have an accuracy of within $3^{\circ}$ and just over $1 \mathrm{~mm}$ of $3 \mathrm{D}$ offset from pre-surgical planning.

2) BLT implants were seen to have an increased degree of inaccuracy compared to BLX implants at the implant platform, but this difference may not be clinically significant.

3) Implants placed in posterior regions of the maxilla demonstrated a greater degree of inaccuracy than those placed in anterior regions. 


\section{References}

1. Abraham CM. A brief historical perspective on dental implants, their surface coatings and treatments. Open Dent J. 2014;8:50-55.

2. Albrektsson T, Jansson T, Lekholm U. Osseointegrated dental implants. Dent Clin North Am. 1986;30(1):151-174.

3. Albrektsson T, Wennerberg A. On osseointegration in relation to implant surfaces. Clin Implant Dent Relat Res. 2019;21 Suppl 1:4-7.

4. Alfadda SA. Early and immediate loading protocols for overdentures in completely edentulous maxillas: a comprehensive review of clinical trials. $J$ Contemp Dent Pract. 2014;15(6):797-805.

5. Bergkvist G. Immediate loading of implants in the edentulous maxilla. Swed Dent J Suppl. 2008(196):10-75.

6. Chmielewski K, Ryncarz W, Yuksel O, et al. Image analysis of immediate fullarch prosthetic rehabilitations guided by a digital workflow: assessment of the discrepancy between planning and execution. Int J Implant Dent. 2019;5(1):26.

7. Cooper L, De Kok IJ, Reside GJ, Pungpapong P, Rojas-Vizcaya F. Immediate fixed restoration of the edentulous maxilla after implant placement. J Oral Maxillofac Surg. 2005;63(9 Suppl 2):97-110.

8. Feine JS, Carlsson GE, Awad MA, et al. The McGill consensus statement on overdentures. Mandibular two-implant overdentures as first choice standard of care for edentulous patients. Gerodontology. 2002;19(1):3-4.

9. Leziy SS, Miller BA. Integrating a Full Digital Workflow to Achieve Optimal Surgical and Restorative Outcomes in Implant Dentistry. Compend Contin Educ Dent. 2019;40(7):414-421; quiz 422.

10. Pauwels R, Araki K, Siewerdsen JH, Thongvigitmanee SS. Technical aspects of dental CBCT: state of the art. Dentomaxillofac Radiol. 2015;44(1):20140224.

11. Peñarrocha-Oltra D, Covani U, Peñarrocha-Diago M. Immediate loading with fixed full-arch prostheses in the maxilla: review of the literature. Med Oral Patol Oral Cir Bucal. 2014;19(5):e512-517.

12. Schincaglia GP, Rubin S, Thacker S, Dhingra A, Trombelli L, Ioannidou E. Marginal Bone Response Around Immediate- and Delayed-Loading Implants Supporting a Locator-Retained Mandibular Overdenture: A Randomized Controlled Study. Int J Oral Maxillofac Implants. 2016;31(2):448-458.

13. Seo C, Juodzbalys G. Accuracy of Guided Surgery via Stereolithographic Mucosa-Supported Surgical Guide in Implant Surgery for Edentulous Patient: a Systematic Review. J Oral Maxillofac Res. 2018;9(1):e1.

14. Meloni SM, De Riu G, Pisano M, Cattina G, Tullio A. Implant treatment software planning and guided flapless surgery with immediate provisional prosthesis delivery in the fully edentulous maxilla. A retrospective analysis of 15 consecutively treated patients. Eur J Oral Implantol. 2010;3(3):245-251. 
15. Bover-Ramos F, Vina-Almunia J, Cervera-Ballester J, Penarrocha-Diago M, Garcia-Mira B. Accuracy of Implant Placement with Computer-Guided Surgery: A Systematic Review and Meta-Analysis Comparing Cadaver, Clinical, and In Vitro Studies. Int J Oral Maxillofac Implants. 2018;33(1):101115.

16. Cassetta M, Giansanti M, Di Mambro A, Stefanelli LV. Accuracy of positioning of implants inserted using a mucosa-supported stereolithographic surgical guide in the edentulous maxilla and mandible. Int J Oral Maxillofac Implants. 2014;29(5):1071-1078.

17. D'Haese J, Van De Velde T, Elaut L, De Bruyn H. A prospective study on the accuracy of mucosally supported stereolithographic surgical guides in fully edentulous maxillae. Clin Implant Dent Relat Res. 2012;14(2):293-303.

18. Pozzi A, Arcuri L, Moy PK. Temporary Shell Proof-of-Concept Technique: Digital-Assisted Workflow to Enable Customized Immediate Function in Two Visits in Partially Edentulous Patients. Compend Contin Educ Dent. 2018;39(3):e9-e12.

19. Tofail SAM, Koumoulos EP, Bandyopadhyay A, Bose S, O'Donoghue L, Charitidis C. Additive manufacturing: scientific and technological challenges, market uptake and opportunities. Materials Today. 2018;21(1):22-37.

20. Turbush SK, Turkyilmaz I. Accuracy of three different types of stereolithographic surgical guide in implant placement: an in vitro study. $J$ Prosthet Dent. 2012;108(3):181-188.

21. Sigcho Lopez DA, Garcia I, Da Silva Salomao G, Cruz Lagana D. Potential Deviation Factors Affecting Stereolithographic Surgical Guides: A Systematic Review. Implant Dent. 2019;28(1):68-73.

22. Van Assche N, Quirynen M. Tolerance within a surgical guide. Clin Oral Implants Res. 2010;21(4):455-458.

23. Zhou W, Liu Z, Song L, Kuo CL, Shafer DM. Clinical Factors Affecting the Accuracy of Guided Implant Surgery-A Systematic Review and Meta-analysis. J Evid Based Dent Pract. 2018;18(1):28-40.

24. Zhao XZ, Xu WH, Tang ZH, Wu MJ, Zhu J, Chen S. Accuracy of computer-guided implant surgery by a CAD/CAM and laser scanning technique. Chin J Dent Res. 2014;17(1):31-36.

25. Aydemir CA, Arisan V. Accuracy of dental implant placement via dynamic navigation or the freehand method: A split-mouth randomized controlled clinical trial. Clin Oral Implants Res. 2020;31(3):255-263.

26. Emery RW, Merritt SA, Lank K, Gibbs JD. Accuracy of Dynamic Navigation for Dental Implant Placement-Model-Based Evaluation. J Oral Implantol. 2016;42(5):399-405.

27. Stefanelli LV, DeGroot BS, Lipton DI, Mandelaris GA. Accuracy of a Dynamic Dental Implant Navigation System in a Private Practice. Int J Oral Maxillofac Implants. 2019;34(1):205-213.

28. Stefanelli LV, Mandelaris GA, DeGroot BS, Gambarini G, De Angelis F, Di Carlo S. Accuracy of a Novel Trace-Registration Method for Dynamic Navigation Surgery. Int J Periodontics Restorative Dent. 2020;40(3):427-435. 
29. Nayar S, Bhuminathan S, Bhat WM. Rapid prototyping and stereolithography in dentistry. J Pharm Bioallied Sci. 2015;7(Suppl 1):S216-219.

30. Cassetta M, Stefanelli LV, Giansanti M, Calasso S. Accuracy of implant placement with a stereolithographic surgical template. Int J Oral Maxillofac Implants. 2012;27(3):655-663.

31. Cassetta M, Giansanti M, Di Mambro A, Calasso S, Barbato E. Accuracy of two stereolithographic surgical templates: a retrospective study. Clin Implant Dent Relat Res. 2013;15(3):448-459.

32. Valente F, Schiroli G, Sbrenna A. Accuracy of computer-aided oral implant surgery: a clinical and radiographic study. Int J Oral Maxillofac Implants. 2009;24(2):234-242.

33. Whitley D, 3rd, Eidson RS, Rudek I, Bencharit S. In-office fabrication of dental implant surgical guides using desktop stereolithographic printing and implant treatment planning software: A clinical report. J Prosthet Dent. 2017;118(3):256-263.

34. Brånemark PI. Osseointegration and its experimental background. J Prosthet Dent. 1983;50(3):399-410.

35. Albrektsson T. Direct bone anchorage of dental implants. J Prosthet Dent. 1983;50(2):255-261.

36. Branemark PI, Adell R, Albrektsson T, Lekholm U, Lundkvist S, Rockler B. Osseointegrated titanium fixtures in the treatment of edentulousness. Biomaterials. 1983;4(1):25-28.

37. Lekholm U. Clinical procedures for treatment with osseointegrated dental implants. J Prosthet Dent. 1983;50(1):116-120.

38. Jensen 0. Site classification for the osseointegrated implant. J Prosthet Dent. 1989;61(2):228-234.

39. Wennerberg A, Albrektsson T. On implant surfaces: a review of current knowledge and opinions. Int J Oral Maxillofac Implants. 2010;25(1):63-74.

40. Papaspyridakos P, Chen CJ, Chuang SK, Weber HP. Implant loading protocols for edentulous patients with fixed prostheses: a systematic review and metaanalysis. Int J Oral Maxillofac Implants. 2014;29 Suppl:256-270.

41. De Bruyn H, Raes S, Ostman PO, Cosyn J. Immediate loading in partially and completely edentulous jaws: a review of the literature with clinical guidelines. Periodontol 2000. 2014;66(1):153-187.

42. Douglass CW, Shih A, Ostry L. Will there be a need for complete dentures in the United States in 2020? J Prosthet Dent. 2002;87(1):5-8.

43. Allen PF, McMillan AS. A review of the functional and psychosocial outcomes of edentulousness treated with complete replacement dentures. J Can Dent Assoc. 2003;69(10):662.

44. Emami E, Heydecke G, Rompré PH, de Grandmont P, Feine JS. Impact of implant support for mandibular dentures on satisfaction, oral and general health-related quality of life: a meta-analysis of randomized-controlled trials. Clin Oral Implants Res. 2009;20(6):533-544.

45. Assunção WG, Barão VA, Delben JA, Gomes EA, Tabata LF. A comparison of patient satisfaction between treatment with conventional complete dentures 
and overdentures in the elderly: a literature review. Gerodontology. 2010;27(2):154-162.

46. Thomason JM. The use of mandibular implant-retained overdentures improve patient satisfaction and quality of life. J Evid Based Dent Pract. 2012;12(3 Suppl):182-184.

47. Alfadda SA, Al-Fallaj HA, Al-Banyan HA, Al-Kadhi RM. A clinical investigation of the relationship between the quality of conventional complete dentures and the patients' quality of life. Saudi Dent J. 2015;27(2):93-98.

48. Hutten MC. Prosthodontic considerations for managing the older adult patient. Gen Dent. 2016;64(6):18-22.

49. Kapur KK, Soman SD. Masticatory performance and efficiency in denture wearers. 1964. J Prosthet Dent. 2004;92(2):107-111.

50. Raghoebar GM, Meijer HJ, Slot W, Slater JJ, Vissink A. A systematic review of implant-supported overdentures in the edentulous maxilla, compared to the mandible: how many implants? Eur J Oral Implantol. 2014;7 Suppl 2:S191201.

51. Fromovich O, Dada K, Pariente L, Daas M. BLX: A new generation of selfdrilling implants. In. BLX magazine. Paris, France: Quintessence; 2019:9-40.

52. Garg AK, Vicari A. Radiographic modalities for diagnosis and treatment planning in implant dentistry. Implant Soc. 1995;5(5):7-11.

53. Monsour PA, Dudhia R. Implant radiography and radiology. Aust Dent J. 2008;53 Suppl 1:S11-25.

54. Greenstein G, Carpentieri JR, Cavallaro J. Dental Cone-Beam Scans: Important Anatomic Views for the Contemporary Implant Surgeon. Compend Contin Educ Dent. 2015;36(10):735-741; quiz742.

55. Aanenson JW, Till JE, Grogan HA. Understanding and communicating radiation dose and risk from cone beam computed tomography in dentistry. $J$ Prosthet Dent. 2018;120(3):353-360.

56. Katsoulis J, Pazera P, Mericske-Stern R. Prosthetically driven, computerguided implant planning for the edentulous maxilla: a model study. Clin Implant Dent Relat Res. 2009;11(3):238-245.

57. Harris BT, Chen L, Lin WS. Digital Imaging and Prosthetic-Driven Implant Planning: Efficient, Accurate, and Reliable Treatment. Compend Contin Educ Dent. 2017;38(7):492-494.

58. Ahuja S, Egbert N, Wicks R, Brandt R. Immediate Implant Prosthesis Via Guided Bone Reduction. Dent Today. 2015;34(7):142-145.

59. Alevizakos V, Mitov G, Stoetzer M, von See C. A retrospective study of the accuracy of template-guided versus freehand implant placement: A nonradiologic method. Oral Surg Oral Med Oral Pathol Oral Radiol. 2019;128(3):220-226.

60. Chen Z, Li J, Sinjab K, Mendonca G, Yu H, Wang HL. Accuracy of flapless immediate implant placement in anterior maxilla using computer-assisted versus freehand surgery: A cadaver study. Clin Oral Implants Res. 2018;29(12):1186-1194.

61. Raico Gallardo YN, da Silva-Olivio IRT, Mukai E, Morimoto S, Sesma N, Cordaro L. Accuracy comparison of guided surgery for dental implants 
according to the tissue of support: a systematic review and meta-analysis. Clin Oral Implants Res. 2017;28(5):602-612.

62. Tan PLB, Layton DM, Wise SL. In vitro comparison of guided versus freehand implant placement: use of a new combined TRIOS surface scanning, Implant Studio, CBCT, and stereolithographic virtually planned and guided technique. Int J Comput Dent. 2018;21(2):87-95.

63. Vermeulen J. The Accuracy of Implant Placement by Experienced Surgeons: Guided vs Freehand Approach in a Simulated Plastic Model. Int J Oral Maxillofac Implants. 2017;32(3):617-624.

64. Vasak C, Watzak G, Gahleitner A, Strbac G, Schemper M, Zechner W. Computed tomography-based evaluation of template (NobelGuide)-guided implant positions: a prospective radiological study. Clin Oral Implants Res. 2011;22(10):1157-1163.

65. Toyoshima T, Tanaka H, Sasaki M, et al. Accuracy of implant surgery with surgical guide by inexperienced clinicians: an in vitro study. Clin Exp Dent Res. 2015;1(1):10-17. 